Article

\title{
New Approach toward Laser-Assisted Modification of Biocompatible Polymers Relevant to Neural Interfacing Technologies
}

\author{
Nadya Stankova 1,*, Anastas Nikolov ${ }^{1}$, Ekaterina Iordanova ${ }^{2}$, Georgi Yankov ${ }^{2}$, Nikolay Nedyalkov ${ }^{1}$, \\ Petar Atanasov $^{1}$, Dragomir Tatchev ${ }^{3}$, Eugenia Valova ${ }^{3}$, Konstantin Kolev ${ }^{3}$, Stephan Armyanov ${ }^{3}$, \\ Daniela Karashanova 4 (D) and Naoki Fukata ${ }^{5}$
}

check for updates

Citation: Stankova, N.; Nikolov, A.; Iordanova, E.; Yankov, G.; Nedyalkov, N.; Atanasov, P.; Tatchev, D.; Valova,

E.; Kolev, K.; Armyanov, S.; et al. New Approach toward Laser-Assisted Modification of Biocompatible Polymers Relevant to Neural Interfacing Technologies. Polymers 2021, 13, 3004. https://doi.org/ $10.3390 /$ polym 13173004

Academic Editor: Daniel Sola

Received: 6 July 2021

Accepted: 1 September 2021

Published: 4 September 2021

Publisher's Note: MDPI stays neutral with regard to jurisdictional claims in published maps and institutional affiliations.

Copyright: (c) 2021 by the authors Licensee MDPI, Basel, Switzerland This article is an open access article distributed under the terms and conditions of the Creative Commons Attribution (CC BY) license (https:// creativecommons.org/licenses/by/ $4.0 /)$
1 Institute of Electronics, Bulgarian Academy of Sciences, 72 Tzarigradsko Shousse Blvd., 1784 Sofia, Bulgaria; anastas_nikolov@abv.bg (A.N.); nnn_1900@yahoo.com (N.N.); paatanas@ie.bas.bg (P.A.)

2 Institute of Solid State Physics, Bulgarian Academy of Sciences, 72 Tzarigradsko Shousse Blvd., 1784 Sofia, Bulgaria; ekiordanova@gmail.com (E.I.); mennefer2@gmail.com (G.Y.)

3 Institute of Physical Chemistry, Bulgarian Academy of Sciences, Acad. Georgi Bonchev Str. Bld.11, 1113 Sofia, Bulgaria; dtachev@ipc.bas.bg (D.T.); jenny@ipc.bas.bg (E.V.); konstantinkolev07@gmail.com (K.K.); armyanov@ipc.bas.bg (S.A.)

4 Institute of Optical Materials and Technologies, Bulgarian Academy of Sciences, G. Bonchev Street, B1. 109, 1113 Sofia, Bulgaria; dkarashanova@yahoo.com

5 International Center for Materials for Nanoarchitectonics (MANA), National Institute for Materials Science (NIMS), 1-1Namiki, Tsikuba 305-0044, Japan; fukata.naoki@nims.go.jp

* Correspondence: nestankova@yahoo.com

Abstract: We report on a new approach toward a laser-assisted modification of biocompatible polydimethylsiloxane (PDMS) elastomers relevant to the fabrication of stretchable multielectrode arrays (MEAs) devices for neural interfacing technologies. These applications require high-density electrode packaging to provide a high-resolution integrating system for neural stimulation and/or recording. Medical grade PDMS elastomers are highly flexible with low Young's modulus $<1 \mathrm{MPa}$ which are similar to soft tissue (nerve, brain, muscles) among the other known biopolymers, and can easily adjust to the soft tissue curvatures. This property ensures tight contact between the electrodes and tissue and promotes intensive development of PDMS-based MEAs interfacing devices in the basic neuroscience, neural prosthetics, and hybrid bionic systems, connecting the human nervous system with electronic or robotic prostheses for restoring and treating neurological diseases. By using the UV harmonics 266 and $355 \mathrm{~nm}$ of Nd:YAG laser medical grade PDMS elastomer is modified by ns-laser ablation in water. A new approach of processing is proposed to (i) activate the surface and to obtain tracks with (ii) symmetric U-shaped profiles and (iii) homogeneous microstructure This technology provides miniaturization of the device and successful functionalization by electroless metallization of the tracks with platinum (Pt) without preliminary sensitization by tin $(\mathrm{Sn})$ and chemical activation by palladium (Pd). As a result, platinum black layers with a cauliflower-like structure with low values of sheet resistance between 1 and $8 \Omega /$ sq are obtained.

Keywords: ns-laser ablation in water; PDMS polymer; electroless metallization; platinum Pt black; neural interfacing technologies; implants

\section{Introduction}

New materials and technologies have been developed in the last two decades for producing multielectrode arrays (MEAs) as interface networks of monitoring and/or stimulation of neural activity and connecting the human nervous system with electronic or robotic prostheses. R. Kim et al. [1,2] and Laing Guo et al. [3] have summarized in detail the fabrication steps of various types of planar multielectrode arrays in sandwich structures for in vitro and in vivo neural interface networks by reviewing technologies' development. 
Briefly, the fabrication steps of such multielectrode structure are the following: choice of material like an insulator, to provide a good electrical signal with minimum attenuation and crosstalks; metal patterning, which includes an engineering design of the number and size of electrodes, interspace interval between electrodes, wire lines, electrical contact pads, metal conductor, and its electrical characteristics (impedance). Medical grade polydimethylsiloxane (PDMS) elastomer is a widely used material in medicine as a carrier material of shunts, pacemakers, and long-term neural implants [1-9]. In the case of the neural implant application, this synthetic polymer is highly preferred for insulator substrate and covering layer for performing stretchable MEAs neural interface devices [1-11]. This is the best alternative for the rigid insulator materials [1-3] (such as silicon dioxide, silicon nitride, or polymers (polyimide, parylene, acrylic imide) with a much higher Young's modulus than of PDMS). The rigid MEAs carriers yield mechanical mismatch and can injure the soft bio-tissues. Medical grade PDMS elastomers can be synthesized as highly flexible with tunable mechanical properties due to the curing temperature and contents ratio. Samples with low Young's modulus of about $1.0 \mathrm{MPa}$ can be obtained with values much closer to those of the nerve $(600 \mathrm{kPa})$, muscles (usually $<100 \mathrm{kPa})$ and brain $(3 \mathrm{kPa})$ tissues [3] than the other insulator materials. Therefore, the PDMS-based MEAs neural devices can easily adjust to the soft tissue surface, conforming to its shape, and ensure tight contact between the electrodes and the neurons, thus optimizing the biological signal recording and/or stimulation. In addition, medical grade PDMS elastomers possess high cytocompatibility and biocompatibility, long-term implant life without disruption of the soft tissues (brain, muscles, and nerves), non-toxicity, high gas permeability, chemical stability, non-flammable, high dielectric breakdown, and high optical transparency in the UV-VIS-NIR spectral range. All these remarkable properties have promoted the intensive research and development of PDMS-based MEAs interface devices in basic neuroscience, neural prosthetics, and hybrid bionic systems, connecting the human nervous system with electronic or robotic prostheses [1-11]. Furthermore, all these hi-tech processes have been devoted to partial restoring of the motor and sensor functions (of limbs or organs) or the cognitive functions lost due to disease or trauma. Simply said, in a human aspect, these scientific efforts are being made for improving the life of people with disabilities. It is worth noting the development of advanced bioelectronic technology referred to as the "bionic

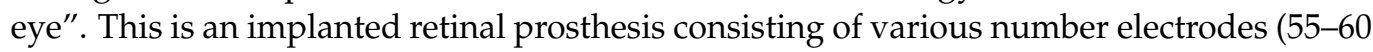
in case of platinum), packed in silicone (PDMS) insulator carrier, for stimulating retinal cells and restoring the sense of sight to patients suffering from retinitis pigmentosa [12].

Micro-channel tracks of noble metal coatings as electrodes, wires, and pads are among the most commonly used in the coplanar PDMS-based MEAs neural interfacing technologies [1-15], because the PDMS polymer provides easy fabrication of MEAs with high-density interconnects and integrated packing. For bioimplants application, thin films of platinum, gold, silver, as well as iridium oxides $\left(\mathrm{IrO}_{x}\right)$, have been used for metal patterns, due to their high biocompatibility and corrosion resistivity. Various innovative approaches [1-15], which combined different methods and materials for preparing insulator substrate, its surface activation, and metal patterning, have been applied to produce high-resolution and high-density integrated PDMS-based stretchable MEAs devices for neural and muscular surface interfacing. Usually, the structure processes are complicated and multi-stepped, which include, for example, e-beam or thermal evaporation; electroplating of metal layers; spin coating and cured of the insulating PDMS layers; modification of PDMS surface from hydrophobic to hydrophilic by using oxygen plasma (shadow masks can be used for selective activation); lift-off method of photoresist by applying UV photolithography or ion etching for metal patterning the sample, etc. Depending on the manufacturing method used, other biocompatible metals such as $\mathrm{Ti}$, Pd and/or Sn can be deposited or other organic (such as 2-hydroxyethyl methacrylate) materials to polymerize [2] and thus to enhance the PDMS adhesion to metal. 
A significant simplification of producing channeled tracks for microelectrodes and microfluidic systems on polymers surface has been offered by applying the laser technique, especially in case of bioapplications.

Medical grade PDMS elastomers and other biocompatible polymers have been very successfully processed by nanosecond and femtosecond lasers, as the first step of fabrication of multielectrode arrays (MEAs) implantable neural devices and microfluidic systems [5,13-23]. Laser-induced local micro-structuring and chemical transformations lead to the formation of a highly active catalytic surface by increasing the surface energy and wettability of the polymers. The surface activation improves significantly the adhesion properties of the laser treated area, which facilitates the second step of the fabrication process, namely, the metal patterning. Metal deposition on the as-modified laser tracks can be conducted very successfully via electroless metallization, which is usually the most applied technique for the metallization of the polymers [24-26].

The main advantages of the laser-assisted fabrication due to which the polymerbased MEAs meet the high-technology demands for implantable neural devices are: (i) increasing the number of electrodes intercontacts by miniaturization of the laser-modified tracks; (ii) inducing effective surface activation and micro-structuring; (iii) contaminantfree processing; and (iv) providing further successful functionalization by deposition of high-quality metal coatings with well-defined microstructure and electrical characteristics.

In our previous investigations [27-32], we reported results on structuring and chemical activation of the surface of medical grade PDMS elastomers by UV, VIS, and NIR ns- and fs-laser processing conducted in air environment. Further, the laser modified PDMS surface has been successfully metalized via electroless plating of $\mathrm{Ni}[27,28]$ or $\mathrm{Pt}[32]$ on the laser tracks. The electroless metallization has been performed successfully without needing the application of the conventional procedure of preceding chemical cleaning and etching for micro-structuring and oxidation of the surface, followed by sensitization with $\mathrm{Sn}$ and chemical activation with Pd. Hydrazine hydrate is used as a reducer in the autocatalytic bath, the $\mathrm{pH}$ of the plating baths is $>12$ and the deposition temperature is set at $70^{\circ} \mathrm{C}$ for $\mathrm{Pt}$ and $80^{\circ} \mathrm{C}$ for Ni deposition. Depending on the hydrazine concentrations, some small differences in the crystallites structure have been observed, although the "spiky" origin remained. The aforementioned process of metallization is found to be much easier to apply than that one applied by Laude et al. [33] and Dupas-Bruzek et al. [34] after laser processing. In addition, selective metallization has been performed without applying masks or external templates. It is also worth noting our findings that the time interval between both processes - the laser treatment and the metallization-is not a critical parameter as it is proposed by Laude et al. [33] and Dupas-Bruzek et al. [34] in their experimental works on UV ns-laser surface modification of medical grade PDMS in air for miniaturization of nerve electrodes and tracks metalized by electroless plating of Pt. Numbers of references reporting on nanosecond or femtosecond laser processing by wavelengths in UV, ViS or NIR spectrum of different polymers (e.g., poly-methyl methacrylate (PMMA), polyethylene terephthalate (PET), polyimide (PI), polystyrene (PS), polycarbonate (PC), polydimethylsiloxane (PDMS)) are available in the literature [13-35]. Producing tracks (channels) and holes on polymer's surface for the development the of micro/nanostructured based devices is of great interest for various applications in microfluidics, micromechanics, photonics, medicine, and biology. The high-quality of the polymers modifications has been evaluated in terms not only of their application purposes, but also in terms of laser control of their optical, wettability and/or structural properties as proposed D. Sola et al. $[21,22,35]$ and other authors N.C.Y. Tham et al. [36], Bahador Farshchian et al. [37], and Carmela De Marco et al. [38]. This depends directly on the physical properties of the material, including optical absorption, thermal conductivity, density, hardness, etc., as well as on the laser beam parameters [13,23]. The ultrashort lasers have gained great attention in material processing due to the higher precision of local treatment in nanometer scale, lower heating effects and absence of redeposition of debris (ejected material) beside the treated zones $[18,28]$. In the case of the 
ns-laser ablation of polymers in air the quality of the tracks and their contours tend to degrade and cannot ensure the high quality of the MEAs characteristics.

Concerning our experimental results, two main disadvantages of the ns-laser ablation of medical grade PDMS can be underlined: (i) the re-deposition of the ablated material (debris) in the zone adjacent to the ablated areas and (ii) the formation of very rough microstructures. However, our experimental findings, especially regarding UV ns-laser ablation, confirmed the results reported by other authors $[26,39,40]$ that the ns-laser treatment of PDMS induced more prominent chemical transformations in the local area of impact rather than the fs-laser irradiation [21,22]. The significant chemical activation of the surface is the reason to prefer ns-laser treatment of PDMS elastomer. Therefore, the production of high-quality traces with well-defined and smooth contours and chemically activated surface by ns-laser irradiation of the biocompatible PDMS polymer without using masks or multiscanning ablation proves to be a great challenge. In this respect an advanced method of laser processing of medical grade PDMS in water surrounding was proposed by Stankova et al. in their 2018 patent application [41] and described in a chapter of the book [42].

Some References as Elaboudi I. et al. [43] report on the comparison between laser ablation efficiency in both air and water environments of polymers such as polymethyl methacrylate (PMMA), ethylene terephthalate (PET), polycarbonate (PC), (polyimide) PI, and polystyrene (PS) by excimer KrF laser. T.C. Chang et al. [44] have explained the dependence of etch depth on the laser energy fluence by existing polymer ablation models observed during $\mathrm{UV}(\mathrm{KrF})$ ablation of PMMA, polypropylene (PP), and polyethylene (PE) in air, methanol and ethyl alcohol. The effects of underwater ablation of PET with $\mathrm{KrF}$ laser on the surface morphology and chemistry has been reported by Jakub Siegel et al. [45]. The quality of channels obtained after ablation of PMMA in different environments (nitrogen, methanol, and water) with UV ( $248 \mathrm{~nm}$ ) laser irradiation has been also investigated for the fabrication of microfluidic systems [46]. Black PMMA has been processed by NIR $(1064 \mathrm{~nm})$ wavelength in both ethanol and water for comparative studying the heat effected zone formation around the laser treated area [47]. However, the laser ablation of PMMA in organic liquid and especially in water resulted in obtaining channels with a wedgeshaped profile. Our preliminary experiments indicate that this type of profile shape could significantly hinder the effective deposition of metal during the autocatalytic metallization. To the best of our knowledge, so far, the production of channels by ns-laser ablation in water of optically transparent PDMS elastomer for MEAs neural implantable devices has not been reported on.

In this article, we report on simple approach for ns-laser ablation of optically transparent medical grade PDMS elastomer (without any UV additives) in a water environment by applying two UV lights (266 and $355 \mathrm{~nm}$ ) of Nd:YAG laser system. To the best of our knowledge, by using this approach, for the first time we obtained free of debris tracks with regular contours and symmetric wide-opened profiles with a rounded (" $U$ ") shape, which provide opportunities for subsequent qualitative functionalization by electroless metallization with platinum $(\mathrm{Pt})$. The laser tracks possess a chemically activated and homogeneous surface microstructure, which ensures on one side the autocatalytic plating of $\mathrm{Pt}$ without preliminary sensitization by $\mathrm{Sn}$ and chemical activation by $\mathrm{Pd}$, and on the other side facilitates the formation of platinum black layers with low sheet resistancebetween 1 and $8 \Omega /$ sq-in terms of their application as PDMS-based stretchable MEAs interfacing devices.

\section{Materials and Methods}

Sheets of medical grade PDMS (MED 4860, NuSil, CA, USA) elastomer (with thickness between 80 and $200 \mu \mathrm{m}$ ), which is optically transparent in the UV-Vis-NIR spectrum, are processed by third $(355 \mathrm{~nm})$ and fourth $(266 \mathrm{~nm})$ harmonics of Q-switched Nd:YAG laser (LOTIS TII LS-2147, Minsk, Belarus) delivering 18 ns laser pulses at a repetition rate of $10 \mathrm{~Hz}$ and multimode laser beam. The samples are placed on the bottom of a glass vessel 
(with size-diameter of $100 \mathrm{~mm}$ and height of $15 \mathrm{~mm}$ ) and immersed in double-distilled water with specific conductivity $1.0 \mu \mathrm{S} \cdot \mathrm{cm}^{-1}$. The water column above the sample surface is kept at a height of $8 \mathrm{~mm}$. At this low height the possibility of the nonlinear absorption of laser beam by water is minimized. The water is set to circulate with a slow flow rate less than $5 \mathrm{~mL} \cdot \mathrm{s}^{-1}$ during the laser treatment, which provides dissipation of the ablated material. The water vessel is placed in another container (tank), which contains coolant with a temperature lower than the room temperature, see Figure 1. The aim is a faster evacuation of the heat delivered by laser irradiation from the ablation zone, and thus the formation of a heat-affected zone to be minimized. The polymer sample, the water container, and the coolant tank are fixed to a computer-controlled $x-y$ axes translation stage. The laser beam is perpendicularly incident on the polymer surface and focused by a lens with a focal length of $100 \mathrm{~mm}$. The focal spot diameter is defined experimentally after 20 pulse shots on the PDMS surface in a water environment for values of the laser energy, at which the efficient ablation starts for wavelengths of $266 \mathrm{~nm}$ and $355 \mathrm{~nm}$, respectively. The laser ablation is performed by a single scanning of the samples in multi-pulse mode. The number of overlapping pulses $N$ is defined by $N=a \cdot f / s$, where $a$ is the laser spot diameter, $f$ is the pulse repetition rate and $s$ is the moving speed of the stage. During all experiments the step of the $x-y$ translating stage is fixed at $12.7 \mu \mathrm{m}$, which determines one-axis speed of $12.7 \mu \mathrm{m} / \mathrm{s}$. Therefore, the number of overlapping pulses per unit area within the spot size is calculated to be 63 pulses for $266 \mathrm{~nm}$ and 72 pulses for $355 \mathrm{~nm}$. The laser fluence is varied from 4.60 to $\sim 50.00 \mathrm{~J} \cdot \mathrm{cm}^{-2}$ at the wavelength of $266 \mathrm{~nm}$ and from 7.70 to $\sim 53.10 \mathrm{~J} \cdot \mathrm{cm}^{-2}$ at the wavelength of $355 \mathrm{~nm}$. The laser beam parameters are listed in Table 1. The values of the laser fluences presented in the table are valid only for the first pulse hitting the polymer. As the laser beam scans the sample surface, the consecutive pulses overlap and cause changes to the PDMS optical properties by the incubation phenomenon. Due to this, defects are induced below the surface, which leads to significant increasing the optical absorption [29] and as a result effective ablation occurs. Continuous laser tracks with desired geometric dimensions (width, depth, length, and shape configuration) are successfully produced by scanning the samples at preliminarily established process parameters.

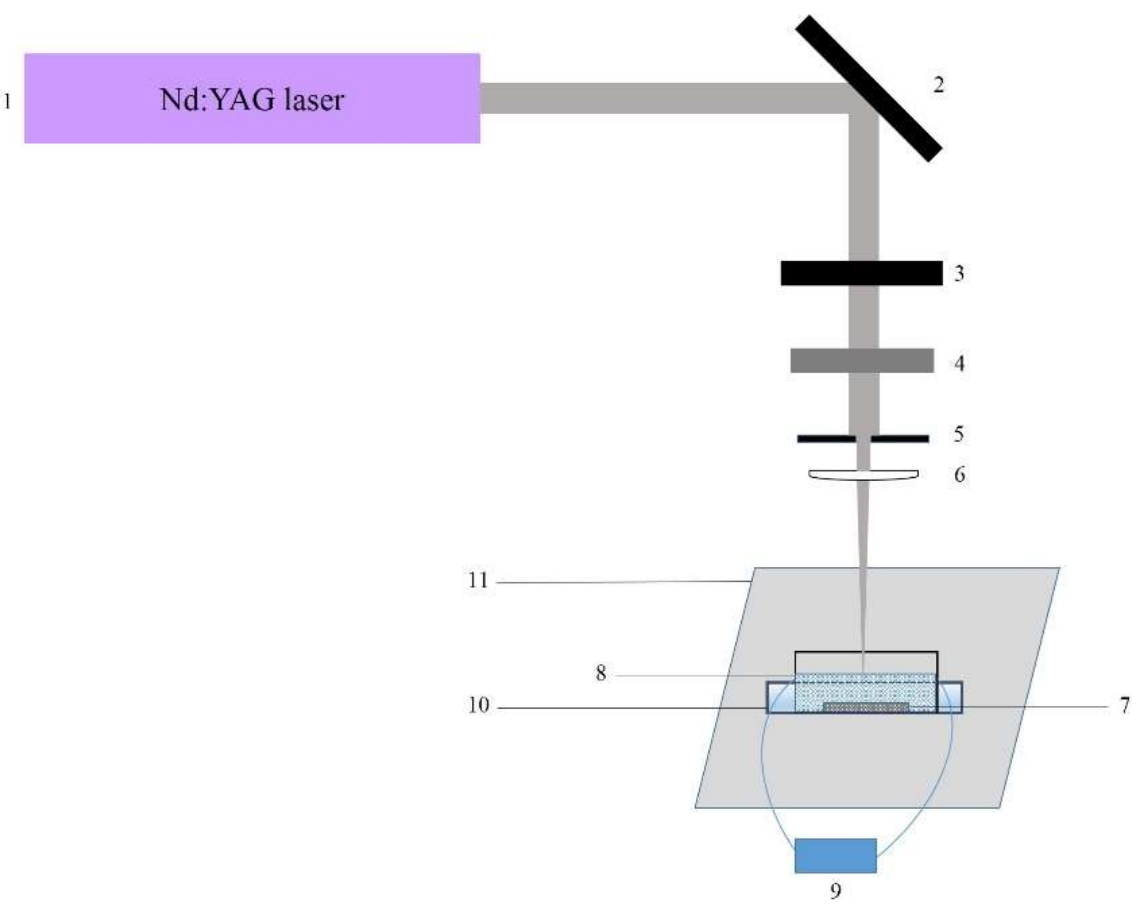

Figure 1. Experimental set-up of laser ablation of PDMS in water: (1)—Nd:YAG laser; (2)—mirror; (3)—attenuator; (4)—shutter; (5)—diaphragm; (6)—lens; (7)—PDMS sample; (8)—vessel with water; (9)—water pump; (10)—coolant tank; (11)— $x$ - $y$ translation stage. 
Table 1. Summary of the laser beam parameters and the size of the tracks after laser treatment of the PDMS surface.

\begin{tabular}{|c|c|c|c|c|c|}
\hline \multirow{2}{*}{$\begin{array}{c}266 \mathrm{~nm} \text { Laser Fluence } \\
\left(\mathrm{J} \cdot \mathrm{cm}^{-2}\right)\end{array}$} & \multicolumn{2}{|c|}{$\begin{array}{c}266 \mathrm{~nm} \\
\text { Track Profile }(\mu \mathrm{m})\end{array}$} & \multicolumn{2}{|c|}{$\begin{array}{c}355 \mathrm{~nm} \\
\text { Track Profile }(\mu \mathrm{m})\end{array}$} & \multirow{2}{*}{$\begin{array}{c}355 \mathrm{~nm} \text { Laser Fluence } \\
\left(\mathrm{J} \cdot \mathrm{cm}^{-2}\right)\end{array}$} \\
\hline & Width & Depth & Width & Depth & \\
\hline 4.64 & - & - & - & - & 7.71 \\
\hline 6.90 & - & - & - & - & 10.62 \\
\hline 10.40 & 90 & 27 & 68 & 25 & 14.05 \\
\hline 12.82 & 109 & 53 & 112 & 33 & 17.30 \\
\hline 17.24 & 128 & 53 & 106 & 64 & 21.75 \\
\hline 22.77 & 136 & 51 & 129 & 67 & 27.06 \\
\hline 28.07 & 144 & 52 & 139 & 82 & 30.83 \\
\hline 35.37 & 160 & 55 & 141 & 98 & 37.68 \\
\hline 42.66 & 183 & 48 & 165 & 78 & 44.53 \\
\hline 49.96 & 207 & 48 & 185 & 90 & 53.10 \\
\hline
\end{tabular}

The PDMS samples are cleaned consecutively with ethanol and deionized water in an ultrasound bath and finally dried by an air stream, before the laser treatment. After laser treatment, the samples are metalized with noble metal Pt by using the electroless deposition technique (autocatalytic bath). The metallization is performed without usually preceding sensitization by $\mathrm{Sn}$ and chemical activation by $\mathrm{Pd}$ of the surface. The electroless plating process is based on a hydrazine hydrate reducer at an optimal concentration determined empirically. The bath for electroless deposition of Pt contains: $\mathrm{K}_{2} \mathrm{Pt}\left(\mathrm{NO}_{2}\right)_{2}, \mathrm{NH}_{4} \mathrm{OH}$, $\mathrm{NH}_{2} \mathrm{OH} \bullet \mathrm{HCl}$, Hydrazine hydrate $\left(80 \% \mathrm{~N}_{2} \mathrm{H}_{4}\right)$. The plating is performed at a temperature of $45{ }^{\circ} \mathrm{C}$ and $\mathrm{pH}$ 11.4. In this case, during the electroless deposition of $\mathrm{Pt}$ evolution of nitrogen gas is possible.

The characterization of the laser processed areas is performed by different analytical techniques including: optical microscopy (Zeiss Opton) for observing the visible permanent surface modifications; VK-9700K Color 3D Laser Microscope (KEYENCE) for viewing the laser trucks' depth and profile; scanning electron microscopy (SEM) with FEG SEM Hitachi SU-70 and SEM/FIB (Lyra/Tescan dual beam system, Brno, Czech Republic) for detailed surface morphological imaging of the laser-treated surface and the Pt coatings structures. $\mu$-Raman spectroscopy (RMS-310 $\mu$-Raman spectrometer (Photon Design, Tokyo, Japan) equipped with a laser operating at a wavelength of $532 \mathrm{~nm}$ ), and X-ray photoelectron spectroscopy (XPS) measurements are performed in a PHI model 5600 system equipped with an Omni Focus Les III (ULVAC-PHI, Chigasaki, Kanagawa, 253-8522, Japan) using a standard Mg K $\alpha$ X-ray source at a high voltage of $15 \mathrm{kV}, 300 \mathrm{~W}$. The PHI Multipak 9 software is used for data treatment and interpretation. The calibration is done by normalizing the $\mathrm{C}$ $1 \mathrm{~s}$ line of adventitious adsorbed hydrocarbons on silver folio to $285.0 \mathrm{eV}$ ) for studying the chemical composition and surface chemical transformations.

\section{Results and Discussion}

\subsection{Laser Processing}

The microchannels on the PDMS surface are fabricated by multipulsed laser ablation in water after single scanning the surface (for each track). The numbers of overlapping pulses $(\mathrm{N})$ for both UV lights are set to be as high as possible allowed by the equipment used. They are limited by the laser spot on the surface, the repetition rate of the laser pulses $(10 \mathrm{~Hz})$, and the stage speed, all of which are fixed. The laser spot size is determined mainly by the lens focus distance $(100 \mathrm{~mm})$ and the wavelength. The minimum moving speed of the stage $(12.7 \mu \mathrm{m} / \mathrm{s})$ is set to ensure precise scanning of the surface. Thus, the energy delivered in a unit area during laser ablation can be controlled by the energy per pulse. Tracks with continuous and uniform ablation depth along their length are obtained at laser fluences higher than $10.40 \mathrm{~J} \cdot \mathrm{cm}^{-2}$ for $266 \mathrm{~nm}$ and at fluences higher than $14.05 \mathrm{~J} \cdot \mathrm{cm}^{-2}$ for $355 \mathrm{~nm}$. These values are higher than the ablation threshold for both wavelengths at multipulsed mode and considered as fluences, at which efficient ablation along the 
track initiates. From Table 1, it is evident that higher values of the laser fluence for the wavelength of $355 \mathrm{~nm}$ are needed in comparison with irradiation at $266 \mathrm{~nm}$ to start laser ablation of PDMS and to cause similar etch depth. These results are consistent with those obtained in our previous investigation of the optical properties of PDMS during ns-laser treatment in air [29]. This dependence can be explained on one side by the lower optical absorption of the material (nearly two times less) at $355 \mathrm{~nm}$ (linear absorption coefficient is about $7.38 \mathrm{~cm}^{-1}$, the penetration depth of $1354 \mathrm{~nm}$ ) concerning this at $266 \mathrm{~nm}$ (linear absorption coefficient is about of $14.9 \mathrm{~cm}^{-1}$, penetration depth of $\left.669 \mathrm{~nm}\right)$, and on the other side by the lower photon energy of the laser irradiation at $355 \mathrm{~nm}(3.5 \mathrm{eV})$. The absorption coefficient and the penetration depth are calculated following the Beer-Lambert law for an average thickness of the sample of $170 \mu \mathrm{m}$, as the scattering losses are ignored. It is worth noting that the absorption and refraction of the laser beam by water can be ignored, since the water absorption at 266 and $355 \mathrm{~nm}$ is very low (the absorption coefficient is of the order between $10^{-3}$ and $10^{-4} \mathrm{~cm}^{-1}$ ), the laser beam is normally incident to the water surface, and the water column height is low enough $(8 \mathrm{~mm})$ to induce nonlinear effects or significant changes of the focused spot size [48] on the sample surface.

According to the investigations reported in the literature [49-54], complex thermodynamic and acousto-mechanical processes take place during laser ablation in water and related effects can be observed: plume expansion, laser-induced cavitation bubbles, bubble collapse, shock waves, etc. In the case of water flow, waves and turbulence can arise and disturb the laser beam propagation. However, studying such processes during laser ablation of PDMS in water is not subject to the current work. During the experiments presented in Section 2, we observed: (i) the formation of visible bubbles and acoustic effects; or (ii) the formation of waves on the air-water interface and water splashes, and the related laser beam propagation perturbance are found to occur when the ablation takes place: (i) simultaneously in still water, high pulse energy delivering $\left(\mathrm{F}_{266} \& 355 \mathrm{~nm}>10 \mathrm{~J} \cdot \mathrm{cm}^{-2}\right)$ (at minimum stage moving speed of $12 \mu \mathrm{m} / \mathrm{s}$ and a high number of overlapping pulses-63 or 72), or at (ii) water column higher than $8 \mathrm{~mm}$ in a narrow vessel with a diameter lower than $50 \mathrm{~mm}$ regardless the pulse energy.

To explain the reasons for this phenomenon additional characterizations and diagnostic techniques should be applied, which will to be the topic of future work.

The presence of bubbles in the zone of laser beam spot during ablation in water is extremely undesirable in our experiments, since they always lead to worsening morphologic quality of the laser-treated surface such as irregular counters, debris and heat-affected zone HAZ could be observed beside the tracks, as it is seen in Figure 2. This is out of the strict demands for producing high-quality neural interface devices, which is our final target.

In this respect, to minimize or even to avoid the effects listed above the output energy per pulse is reduced nearly 8 times by an attenuator and a diaphragm both placed in the beam propagation path (before the lens). A water pump is mounted to keep slow flow rate between 3 and $5 \mathrm{~mL} \cdot \mathrm{s}^{-1}$. According to the results obtained, this flow rate is high enough for decreasing the plasma shielding effect (laser beam absorption by the plasma plume) and removing debris far from the ablation zone. Empirically, it has been established at this range of rate values the flow prevents the formation of bubbles during the ablation. Moreover, cooling the water additionally by coolant keeps its temperature lower enough than the room temperature. We believe that cool water contributes to (i) increase the convective heat transfer near the zone of ablation due to the temperature gradient induced by both the coolant and the water flow, and to (ii) enhance the dissipation of the ablated material and move it away from the ablation zone in addition to the water flow effect. Also, flow rate and cooling of the water, reduce the formation of HAZ near the laser-treated zone, proven by optical microscopy images in Section 3.2.

If the flow rate increases higher than $5 \mathrm{~mL} / \mathrm{s}$, the formation of bubbles in the ablation zone and waves at the air-water interface are also observed. Moreover, bubbles are observed to form more often at irradiation with a wavelength of $355 \mathrm{~nm}$ rather than $266 \mathrm{~nm}$. This could be due to the higher thermal effect induced when higher energy is delivered through 
the water during irradiation with $355 \mathrm{~nm}$ compared to the irradiation with $266 \mathrm{~nm}$, as is commented above and in detail in our previous work [29].

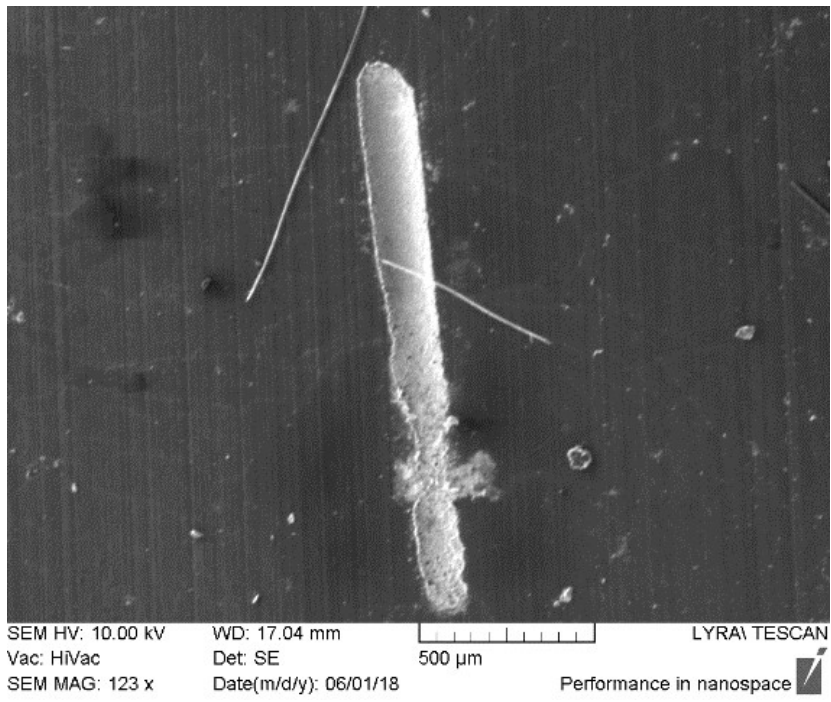

(a)

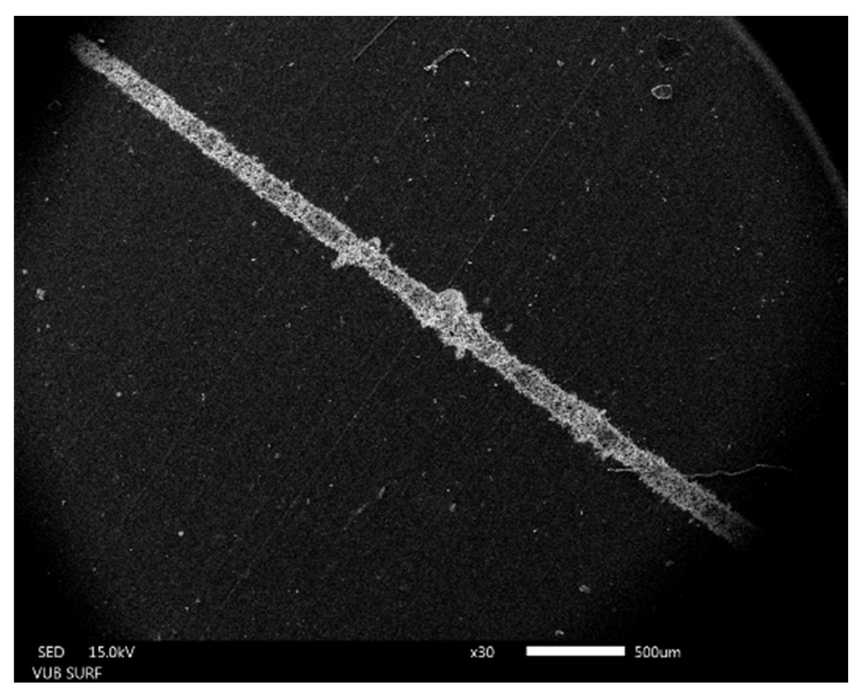

(b)

Figure 2. SEM images of tracks with worsening morphologic quality obtained on PDMS surface by laser ablation in water with wavelengths of: (a) $266 \mathrm{~nm}$ and $28.07 \mathrm{~J} \cdot \mathrm{cm}^{-2}$ and (b) $355 \mathrm{~nm}$ and $30.83 \mathrm{~J} \cdot \mathrm{cm}^{-2}$ when bubbles are induced in the zone of the laser beam spot. The tracks are metalized with Pt.

Additionally, the water volume and the vessel dimensions are found to be crucial for the formation of waves on the air-water interface and water splashes during the laser ablation. The water column height between 8 and $10 \mathrm{~mm}$ poured in wide (diameter of about $10 \mathrm{~mm}$ ) and shallow vessel (with height up to $20 \mathrm{~mm}$ ) is empirically established as optimal to avoid the indicated effects during ablation with laser fluences higher than $10 \mathrm{~J} \cdot \mathrm{cm}^{-2}$ at both wavelengths.

Besides the laser-induced cavitation bubbles, other causes that could contribute to bubble formation should be considered. The chemical structure of PDMS consists of repeating monomer $\left[\mathrm{SiO}\left(\mathrm{CH}_{3}\right)_{2}\right]$ units with the main chain of $\mathrm{Si}-\mathrm{O}-\mathrm{Si}$ and $\mathrm{CH}_{3}$ radicals bonded to the Si. Therefore, during the laser ablation of PDMS elastomer an evolution of C-radicals, $\mathrm{CO}_{2}$, and/or molecular oxygen $\left(\mathrm{O}_{2}\right)$ is possible [39]. The formation of inorganic products such as crystal silicon (c-Si) and crystalline and amorphous phases of carbon, confirmed by $\mu$-Raman spectroscopic and XPS measurements in zones of the laser-treated area, supports this assumption. In addition, by using transmission electron microscopy (TEM), the images are presented in Figure 3, an investigation of the plasma plume products deposited on copper grids during the ns-laser ablation of PDMS in air with $266 \mathrm{~nm}$ and $355 \mathrm{~nm}$ reveals the presence of polycrystalline SiC and crystal Si phases. The carbon phases are not revealed since the grids are carbon-supported. The presence of inorganic products in the plasma plume during the ablation of PDMS proves its chemical decomposition, which is related to releasing the gaseous phases, as mentioned above. Also, the evaporation of water in the near field of the laser beam could occur, because of the increasing local temperature due to the highly intensive UV laser irradiation and following ablation dynamics effects. This is possible to induce the decomposition of water. The gaseous species can be released and expelled along with the other particles in the plasma plume and thus give their contribution to the formation of the bubbles. However, our observation is that once the bubbles are formed above the sample surface it expands and the quality of the laser track drops dramatically. 


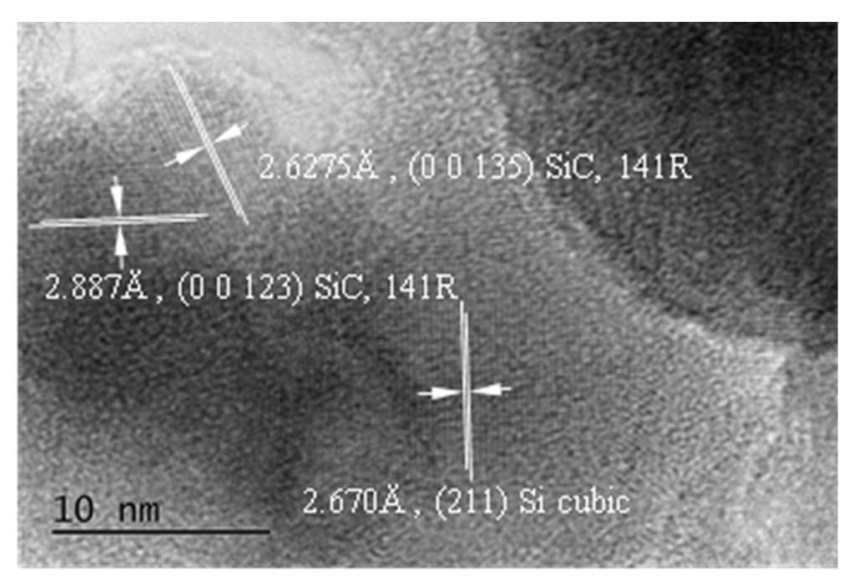

(a)

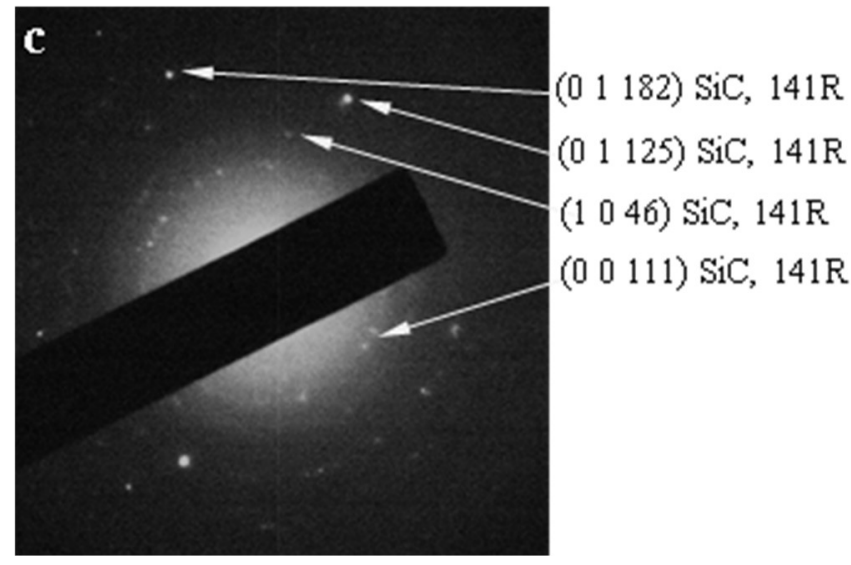

(b)

Figure 3. HRTEM (a) and SAED (b) images of the plasma plume products deposited on copper grids during the ns-laser ablation of PDMS in air with $266 \mathrm{~nm}$ and fluence $\sim 4 \mathrm{~J} \cdot \mathrm{cm}^{-2}$ reveal presence of polycrystalline SiC and crystal Si phases.

Our preliminary experimental investigation credibly contributes to the establishment of the optimal process parameters shown in Table 1 and described in Section 2, at which the hydrodynamic and plasma dynamics effects, described above, as well as the re-deposition of the ablated material beside the tracks and HAZ formation during the ns-laser ablation of PDMS polymer in water can be decreased or avoided. The adjustment of all processing parameters (laser fluences between 10.40 and $49.96 \mathrm{~J} \cdot \mathrm{cm}^{-2}$ for $266 \mathrm{~nm}$ and between 14.05 and $44.53 \mathrm{~J} \cdot \mathrm{cm}^{-2}$ for $355 \mathrm{~nm}$, high number of pulses, water flow rate $<5 \mathrm{~mL} / \mathrm{s}$ and column height of $8 \mathrm{~mm}$ ) allow the production of high-quality laser tracks with tunable size and well-defined open "Ü"- shaped profile in accordance with the application requirements for achieving high-definition tracks free of debris. It is important to emphasize that the tracks obtained by ablation with $266 \mathrm{~nm}$ revealed more uniform and homogeneous microstructure along the length possibly due to the higher optical absorption yielding more efficient ablation in comparison to the laser irradiation generated at a wavelength of $355 \mathrm{~nm}$.

\subsection{Morphological Structure}

In our previous investigations reported in Refs. [27,29] the direct ns-laser writing on PDMS MED 4860 surface in air environment by using wavelengths 266, 355, 532, and $1064 \mathrm{~nm}$ have always revealed one drawback-re-deposition of the ablated material (debris), which has also been reported in ref. [18,20]. During multi-pulse laser ablation, the ejected material is deposited on the pristine surface adjacent near to the laser-treated area as is shown in Figure 4a. The debris are highly undesirable since incorporate a negative effect on the process of subsequent functionalization of the as-modified surface by electroless $\mathrm{Pt}$ metallization. Most of the Pt ions contained in the metallization bath are deposited predominantly on the debris ejected beside the tracks, see Figure $4 \mathrm{~b}$. This leads to a rapid depletion of the $\mathrm{Pt}$ ions contained in the plating bath and wasting an expensive noble metal such as platinum is. This, in turn, is a precondition for several undesirable effects, which can worsen the microelectrodes arrays' quality and inability to miniaturize the chip (namely, inability to increase the number of the tracks) as well as a short circuit between the metalized tracks. Therefore, to meet the requirements for precise and high definition MEAs devices for neural implantable interfacing technologies, is necessary to obtain highquality laser modification by excluding re-deposition of debris and thus to increase the number of tracks (electrodes) per unit area, i.e., miniaturization of the chip. Production of free of debris laser-processed tracks permit their further successful functionalization by Pt coatings. 

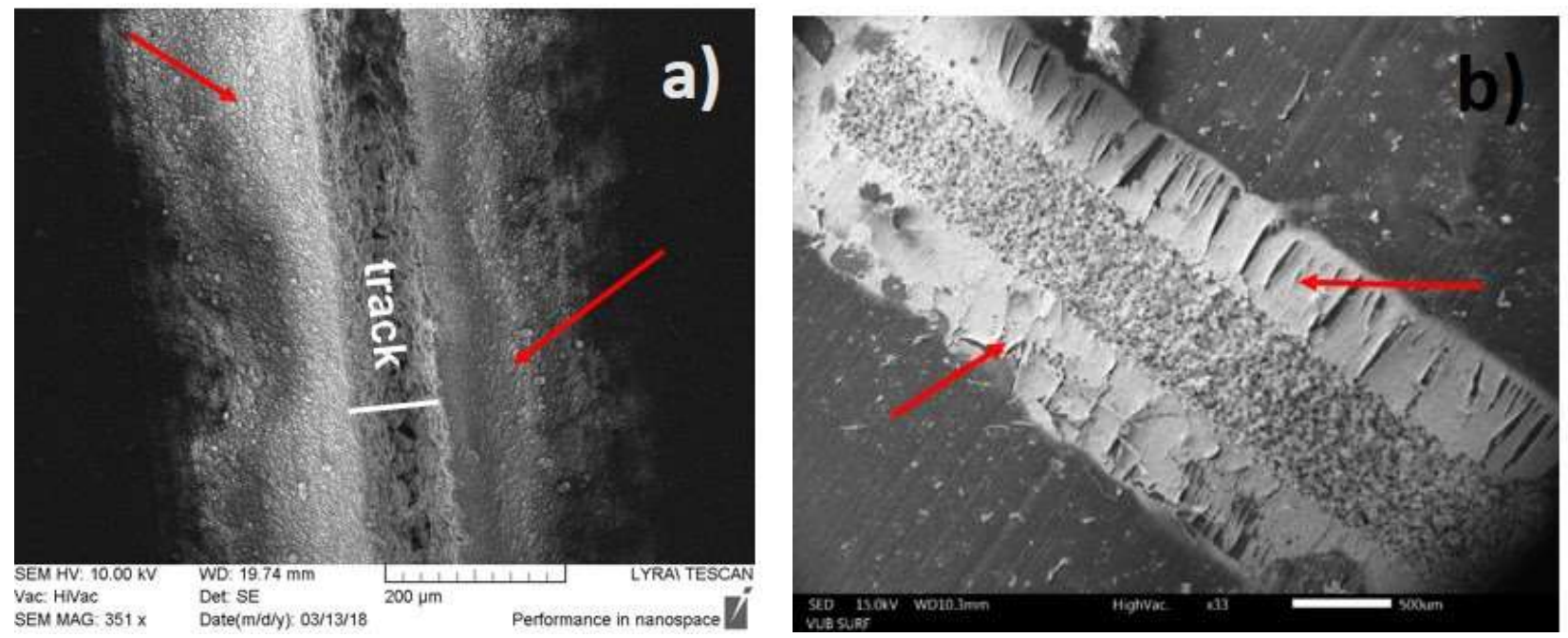

Figure 4. (a) Laser track after ns-laser ablation of PDMS sample in air with a wavelength of $266 \mathrm{~nm}$, the beam spot is in the focal plane, the red arrows show the debris beside the track; (b) Pt (platinum) coating deposited by electroless metallization of a track obtained by ns-laser ablation of PDMS sample in air with $266 \mathrm{~nm}$ wavelength, the beam spot is out of the focal plane, the red arrows show the debris beside the track, on which enough quantity of Pt is deposited.

The other observed disadvantage of the ns-laser ablation of this polymer in air environment is the formation of the wedge-shaped profile of the channels, which are obtained after ablating in the focal plane of the lens (see Figure 4a) for obtaining the small-sized track. Also, the formation of rough and inhomogeneous relief with deep pores inside the tracks interferes with further deposition of a continuous metal layer, and as a result the electric circuit could not be qualitative and reliable for the intended application as MEAs.

To overcome these shortcomings, we successfully provide two different approaches of ns-laser processing of PDMS elastomer substrates. The first one is laser processing on the polymer surface by laser ablation in water [41,42]. The second one is the ablation in air of the PDMS surface, which preliminary is pre-coated with a thin layer of PMMA by spraying. Here, after performing ablation in air this thin film of PMMA is removed by cleaning in an ultrasonic bath.

During the one-scanned multi-pulsed laser ablation in water tracks with homogeneous depth and well-defined borders are obtained at fluences higher than $10.40 \mathrm{~J} \cdot \mathrm{cm}^{-2}$ and $14.05 \mathrm{~J} \cdot \mathrm{cm}^{-2}$ at wavelengths of $266 \mathrm{~nm}$ and $366 \mathrm{~nm}$, respectively. No evidence of deposition of ejected material and heat-affected zone is observed near the place of ablation. The produced tracks are free of debris with uniform nanostructured relief (see in Figure 5). The profiles with regular contours and wide-opened symmetric U-shape are formed as a result, (Figure 6). The ablation at lower fluences is not efficient and the laser tracks obtained are not continuous along their longitudinal direction and also lose their linear contours.

Highlighting, the tracks obtained by ns-laser processing of PDMS elastomer in water, especially with a wavelength of $266 \mathrm{~nm}$ and fluences higher than $10.40 \mathrm{~J} \cdot \mathrm{cm}^{-2}$, are of very high quality, perfectly comparable with the quality of these produced by fs-laser processing of PDMS samples in air environment, reported previously in our works $[27,28,31]$ as well as by F. Baset et al. [18]. Briefly, the ns-laser processing of PDMS elastomer in water causes the formation of a similar nanostructured surface with uniform relief topography, wide-open tracks with regular borders, as is evident from the electron and the optical microscopes images, Figure 5. A comparison with the results obtained after laser processing of polymers (PMMA, PDMS, PGS, APS) and already reported by other authors $[13,17,38]$ revealed that we have succeeded to produce these high-quality laser tracks by applying only onescanning ablation with multimode nanosecond laser irradiation at a low repetition rate. Namely, for such parameters, the nanosecond lasers are avoided using for micromachining, because of the lower quality (in terms of the characteristics described above) of the laser tracks compared to the femtosecond lasers abilities. 


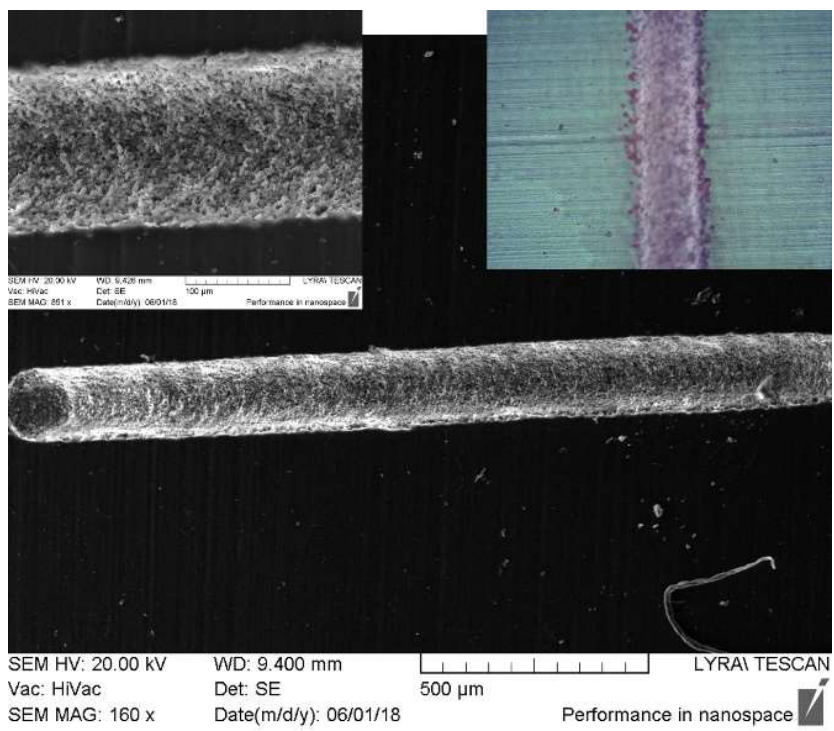

(a)

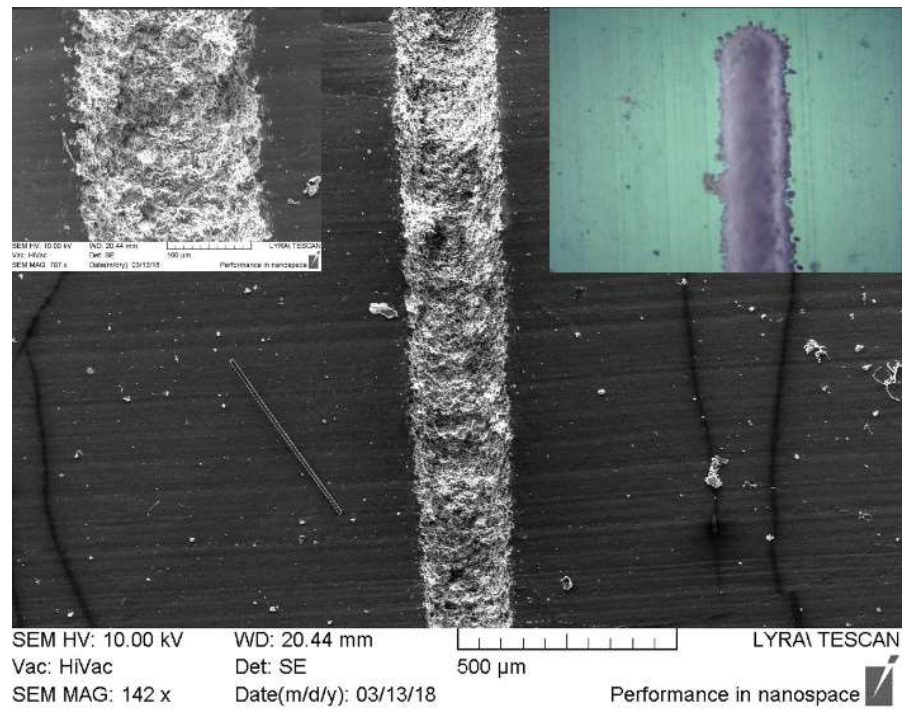

(b)

Figure 5. SEM images in different magnifications are applied in order to demonstrate production of free of debris laser tracks after ns-laser ablation of PDMS polymer in water. No evidence of deposition of ejected material and heat-affected zone is observed near the place of ablation. The insets present higher magnification of the SEM images and images taken by optical microscope: (a) $266 \mathrm{~nm}$ and fluences higher than $28.07 \mathrm{~J} \cdot \mathrm{cm}^{-2}$; (b) $355 \mathrm{~nm}$ and fluences higher than $21.75 \mathrm{~J} \cdot \mathrm{cm}^{-2}$.

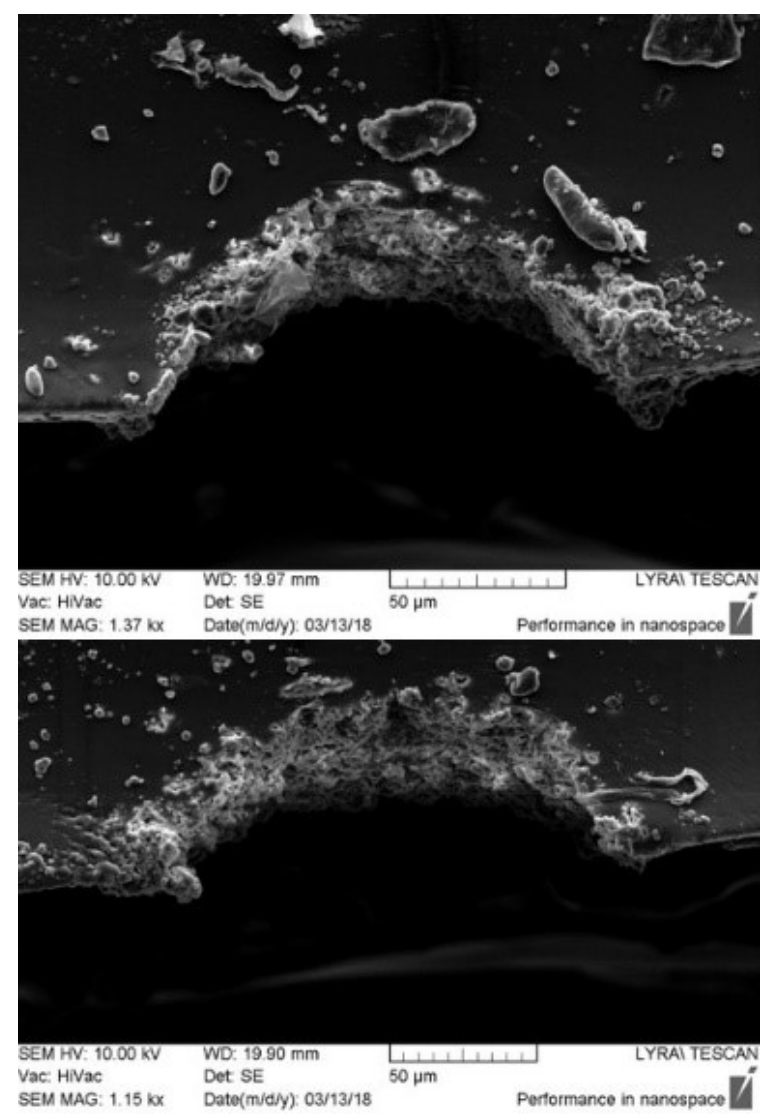

(a)

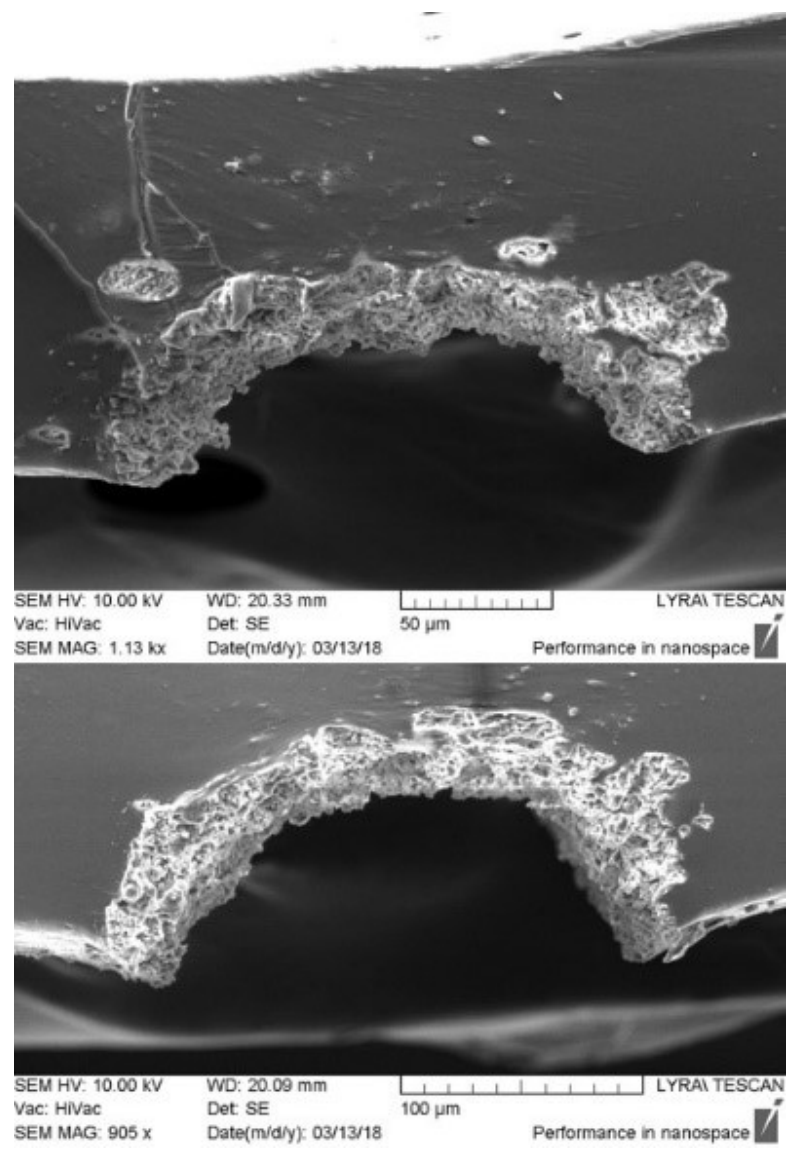

(b)

Figure 6. SEM cross section images of the laser tracks produced after ns-laser ablation of PDMS polymer in water present the formation of Profiles with regular contours, and symmetric and wide-opened U-shape, with: (a) $266 \mathrm{~nm}$ and fluences higher than $28.07 \mathrm{~J} \cdot \mathrm{cm}^{-2}$; (b) $355 \mathrm{~nm}$ and fluences higher than $21.75 \mathrm{~J} \cdot \mathrm{cm}^{-2}$. 
The size of channels becomes smoothly wider and deeper at both wavelengths applied by increasing the energy, as is expected. However, it is observed that the profile width increases faster than the profile depth with increasing laser fluence for both wavelengths applied. This could be due to hydrodynamic effects related to the plume expansion and water confinement during the ablation, and to the applied laser energy, all in a strong correlation to the material properties. The channels' width and depth can be easily controlled considering their strong dependence on the laser fluence. Corresponding values are shown in Table 1.

Attention must be drawn to the comparison of the channels' profiles produced by laser ablation in a different environment-air and water-showing two intriguing peculiarities: (1) by increasing laser fluence the width and depth also increase, valid for both environments; (2) in air deep V-shaped profiles are formed like in ref. [17], which reports the same profile shape after single-scanning fs-laser ablation of polymers (PMMA, PS) with a wavelength in NIR spectrum-800 nm and formation of highly open U-shaped profiles after multiscanning ablation. While in the case of single-scanning nanosecond laser ablation in water the profiles are wide open with a symmetrical U-shape. To summarize, the water contributes to the high-quality performance of the laser tracks simultaneously by carrying the debris away and promoting the formation of desirable profiles shape, in terms of the intended MEAs application. An explanation of the difference between profiles obtained after ablation in air and water could be given after applying characterizations and diagnostic techniques, which are not the subject of this topic. However, we assume that the prominent difference is due to the different physics effects that occur during ns-laser ablation in air and water. As in the case of ablation in water environment, correspondingly related processes can increase the laser ablation efficiency. In water environment additionally to the impacts of plasma expansion dynamics, intense water jet-induced impulses can be produced due to the cavitation bubble collapse in the vicinity of the polymer surface [55]. Also, the water confinement effect can increase the backpressure (recoil) effect on the laser-treated zone during plasma expansion $[43,49,54]$. Further, modulations in quantum mechanical aspect (such as decreasing of the phase velocity of the photons and increase of their momentum can be responsible [56], and geometric distribution transformations [48] of the laser beam could be expected during its propagation in the dispersive media with a refractive index higher than 1 such as the water is, despite the low height of the water column.

The 3D color laser microscope analysis confirms the results obtained by scanning electron microscopy. Examples of tranches, produced by $266 \mathrm{~nm}$ and laser fluence of $49.96 \mathrm{~J} \cdot \mathrm{cm}^{-2}$, and the tranches, produced by $355 \mathrm{~nm}$ and laser fluence of $37.68 \mathrm{~J} \cdot \mathrm{cm}^{-2}$, are presented in Figure 7a,b, respectively. As it can be seen, clear and well-defined tranches with homogeneous surface microstructure are produced in both cases. The profiles' shape seems perfectly symmetrical. Moreover, no debris redeposited and not affected zone adjacent near to the tranches are observed. This picture is typical for the tracks produced at fluences higher than $10.40 \mathrm{~J} \cdot \mathrm{cm}^{-2}$ and $14.05 \mathrm{~J} \cdot \mathrm{cm}^{-2}$ at wavelengths of $266 \mathrm{~nm}$ and $366 \mathrm{~nm}$, respectively, especially at $266 \mathrm{~nm}$.

By controlling the translation of the $x-y$ stage different configurations of tracks can be obtained. It allows the complex design of microelectrode arrays relevant to the specific technology requirements. Particular structures with specific size and shape characteristics (depth, width, profile shape) could be obtained under controlling laser fluence, moving stage speed (respectively, the number of overlapping pulses) as well as the water parameters (column height, flow rate, temperature, water purity). According to our experimental findings, the optimal laser fluences, which provide conditions for high quality and permanent stability of the ns-laser ablation performance are fluences higher than $10.40 \mathrm{~J} \cdot \mathrm{cm}^{-2}$ for $266 \mathrm{~nm}$ and $14.05 \mathrm{~J} \cdot \mathrm{cm}^{-2}$ for $355 \mathrm{~nm}$, especially at $266 \mathrm{~nm}$ for higher optical absorption of the PDMS elastomer at this wavelength.

It is important to underline that treating the sample in water with a specific electrical conductivity less than or equal to $1.0 \mu \mathrm{S} \cdot \mathrm{cm}^{-1}$, the resulting structure is applicable for medical purposes. 


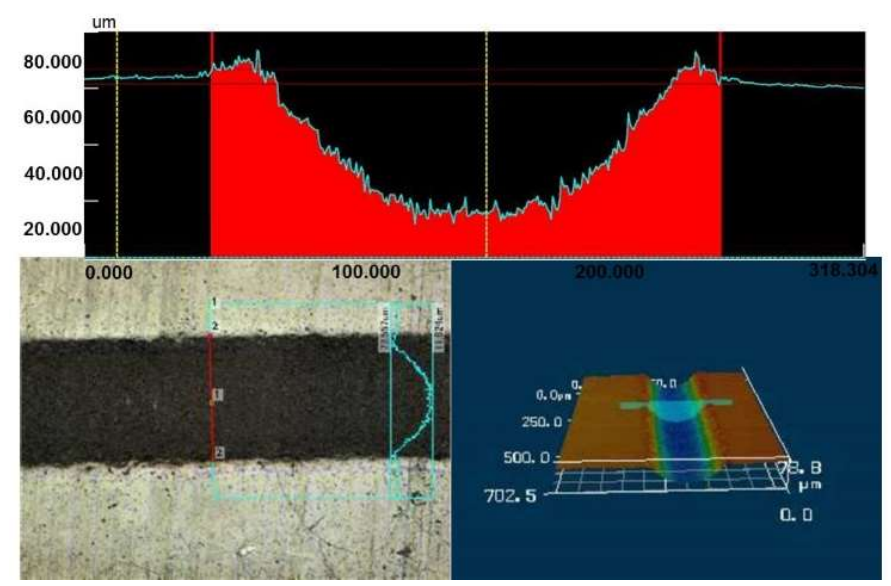

(a)

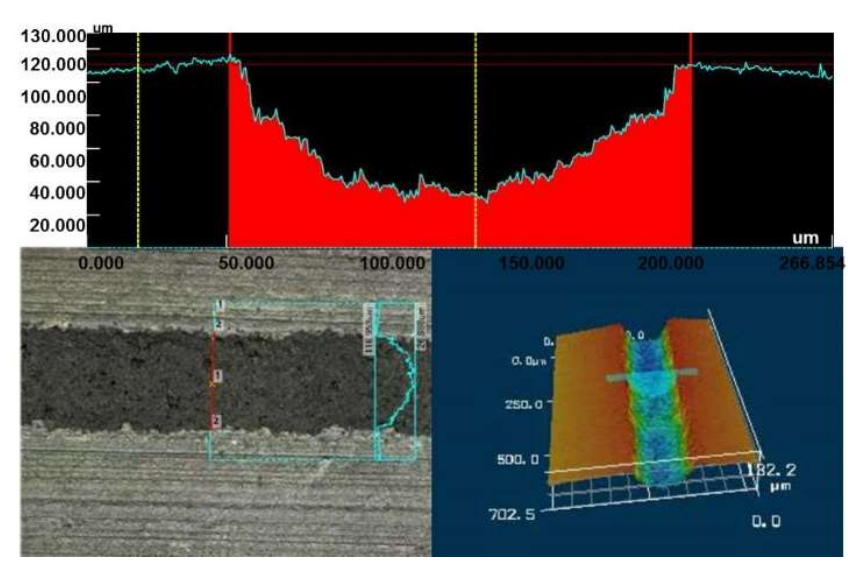

(b)

Figure 7. 3D Laser microscope views of the tracks produced by: (a) $266 \mathrm{~nm}$ laser pulses with fluence $42.66 \mathrm{~J} \cdot \mathrm{cm}^{-2}$; and (b) $355 \mathrm{~nm}$ laser pulses with fluence $37.68 \mathrm{~J} \cdot \mathrm{cm}^{-2}$. It can be seen no debris are re-deposited after laser ablation near the tracks. HAZ also is not formed.

\subsection{Chemical Composition}

XPS study of the surface structure of PDMS reveals that chemical degradation occurred after UV laser treatment in water. The results of $\mathrm{Si}(-\mathrm{O}) \mathrm{n}$ components in $\mathrm{Si} 2 \mathrm{p}$ and $\mathrm{O} 1 \mathrm{~s}$ peaks are presented in Table 2 after their deconvolution. The binding energy (BE) value at $101.63 \mathrm{eV}$ is assigned to a pristine organic silicone phase or PDMS backbone Si(-O)2. While the peaks $\mathrm{Si}(-\mathrm{O}) 3$ at $102.6 \mathrm{eV}$ and $\mathrm{Si}(-\mathrm{O}) 4$ at $103.3 \mathrm{eV}$ measured in the laser-treated area correspond to the inorganic silica-like ( $\mathrm{SiOx}$ ) phase. The portions ratio between pristine and processed surface could be presented as approx. $60 \%: 40 \%$. The high portion of inorganic silicon indicates that the PDMS surface suffered significant chemical changes after laser exposure as it was observed to happen after laser ablation in air. The deconvolution of the $\mathrm{O} 1 \mathrm{~s}$ peak reveals a hydroxyl group $(-\mathrm{OH})$, which is attached to the organic molecule by the appearance of a peak at $532.55 \mathrm{eV}$. This binding energy value can be assigned to the formation of a $\mathrm{Si}(-\mathrm{OH})$ functional group, which confers the hydrophilic properties of the laser-treated surface. The portion of $\mathrm{Si}(-\mathrm{OH})$ is $17.3 \%$ when processing is performed in water (see Table 2) with respect to $4 \%$ when processing is in air (established in previous our works $[30,31])$. Increasing the $\mathrm{Si}(-\mathrm{OH})$ component after laser ablation in water is considered as one of the main factors providing to a great extent of the hydrophilicity and the highly efficient deposition of Pt only on the processed area via electroless metallization-which is one wet process taking place in a complex chemical solution. The results presented in Table 2 correlate to curves of $\mathrm{O} 1 \mathrm{~s}$ and Si 2p peaks, presented in Figure 8.

Table 2. Comparison of XPS data of the PDMS surface after ns-laser ablation within water and air.

\begin{tabular}{|c|c|c|c|c|c|c|c|c|}
\hline \multirow[t]{2}{*}{$\begin{array}{l}\text { Ns-Laser } \\
\text { Ablation }\end{array}$} & & \multicolumn{3}{|c|}{$\begin{array}{l}\text { Silicon Chemical Environments and } \\
\text { the Corresponding Si } 2 p \text { BE }\end{array}$} & \multicolumn{4}{|c|}{$\begin{array}{l}\text { Oxygen Chemical Environments and the } \\
\text { Corresponding O 1s BE. }\end{array}$} \\
\hline & & $\mathrm{CH}_{3}$ & $\mathrm{O}$ & $\mathrm{O}$ & $\mathrm{OH}$ & $\mathrm{CH}_{3}$ & $\mathrm{O}$ & $\mathrm{O}$ \\
\hline \multirow{5}{*}{ In water } & Chemical Structure & $\mathrm{O}-\mathrm{Si}-\mathrm{O}$ & $\mathrm{O}-\mathrm{Si}-\mathrm{O}$ & $\mathrm{O}-\mathrm{Si}-\mathrm{O}$ & $\mathrm{O}-\mathrm{Si}-\mathrm{O}$ & $\mathrm{O}-\mathrm{Si}-\mathrm{O}$ & $\mathrm{O}-\mathrm{Si}-\mathrm{O}$ & $\mathrm{O}-\mathrm{Si}-\mathrm{O}$ \\
\hline & & $\mathrm{CH}_{3}$ & $\mathrm{CH}_{3}$ & O & $\mathrm{CH}_{3}$ & $\mathrm{CH}_{3}$ & $\mathrm{CH}_{3}$ & $\mathrm{O}$ \\
\hline & Abbreviation & $\mathrm{Si}(-\mathrm{O}) 2$ & $\mathrm{Si}(-\mathrm{O}) 3$ & $\mathrm{Si}(-\mathrm{O}) 4$ & $\mathrm{Si}(-\mathrm{OH})$ & $\mathrm{Si}(-\mathrm{O}) 2$ & $\mathrm{Si}(-\mathrm{O}) 3$ & $\mathrm{Si}(-\mathrm{O}) 4$ \\
\hline & Experimental BE (eV) & 101.63 & 102.60 & 103.30 & 530.55 & 531.65 & 532.49 & 533.11 \\
\hline & Reference BE (eV) & 101.79 & 102.67 & 103.30 & 530.60 & 532.00 & & 533.20 \\
\hline In water & $\begin{array}{l}\text { Calculated from fitting in } \\
\text { Figure } 8(\%)\end{array}$ & 59.80 & 37.80 & 2.40 & 17.30 & 62.00 & 15.50 & 5.20 \\
\hline In air & $\begin{array}{l}\text { Calculated from fitting in } \\
\text { Figure } 8(\%)\end{array}$ & 25.06 & 12.80 & 62.14 & 4.00 & 32.16 & 21.78 & 41.66 \\
\hline
\end{tabular}



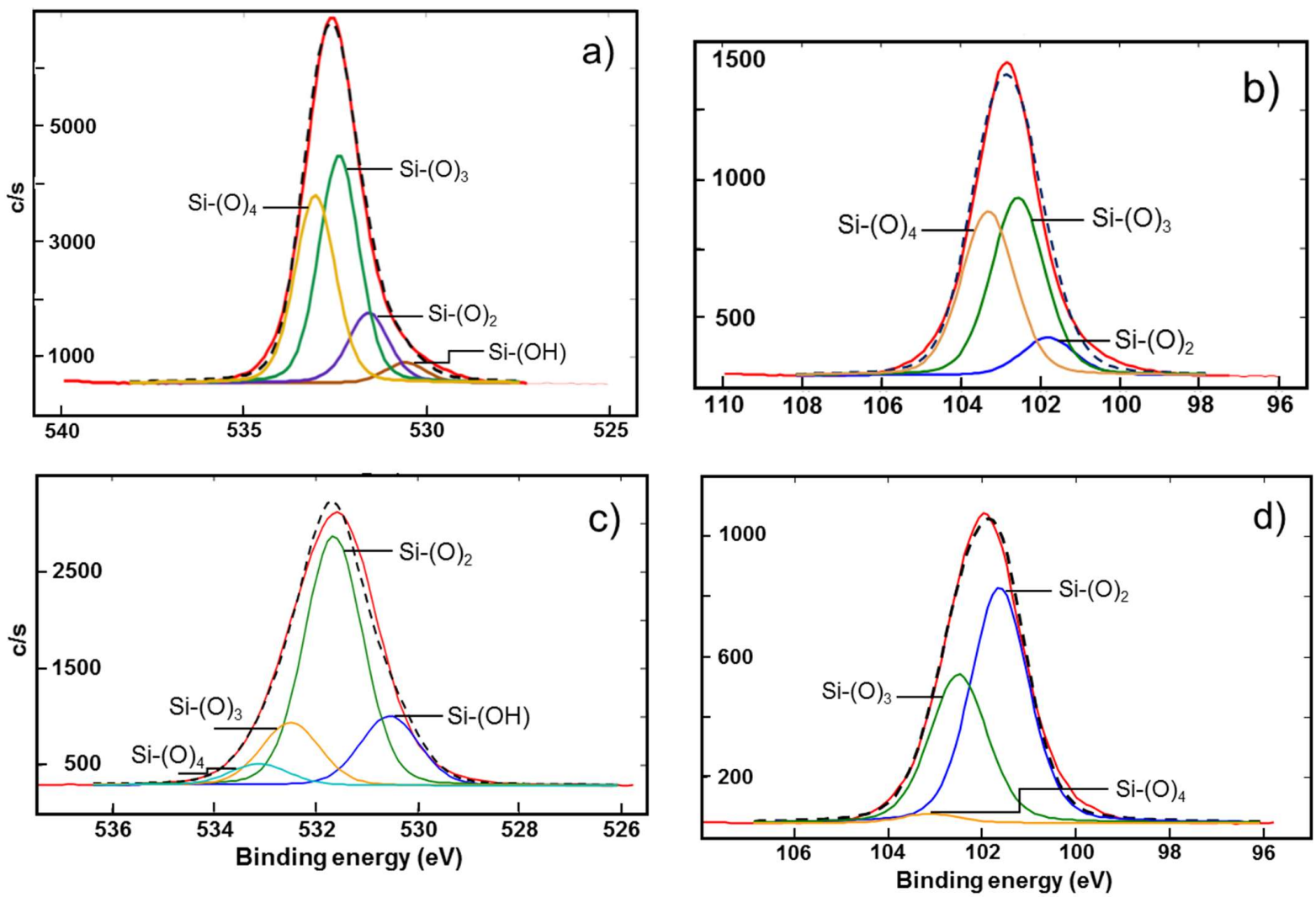

Figure 8. Curves fitting of XPS spectra of O1 s (a,c) and Si 2p (b,d). Laser ablation of PDMS with $266 \mathrm{~nm}$ : (a,b) in air with fluence $4.3 \mathrm{~J} \cdot \mathrm{cm}^{-2} ;(\mathbf{c}, \mathbf{d})$ in water with fluence $28.07 \mathrm{~J} \cdot \mathrm{cm}^{-2}$. Dashed line is the fitting curve.

These results are convincingly confirmed by measurements with $\mu$-Raman spectroscopy of the samples processed by UV laser in water. A strong and sharp peak appeared at $516 \mathrm{~cm}^{-1}$ and shifted to $520 \mathrm{~cm}^{-1}$ with increasing the laser fluence for the case of both wavelength (266 and $355 \mathrm{~nm}$ ) applied. The peak is ascribed to mono and/or polycrystalline silicon (c-Si). Also, it is observed that its intensity raises with laser fluence, whereas the intensity of the peak at $489 \mathrm{~cm}^{-1}$, corresponding to the O-Si-O, sharply dropped, see Figure 9. The same tendency is observed for PDMS samples irradiated in air with ns-laser wavelengths in the UV-ViS-NIR spectrum range.

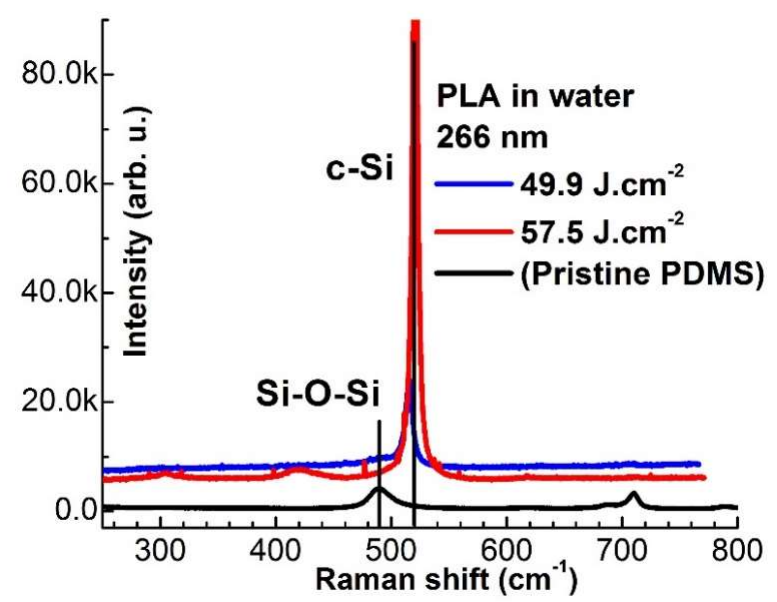

Figure 9. Raman spectra of PDMS polymer processed by $266 \mathrm{~nm}$ laser pulses in a water environment. Similar Raman spectra are obtained after processing with $366 \mathrm{~nm}$. The Raman spectra demonstrate chemical activation of the surface after UV laser treatment with all fluences applied. 
To emphasize, both analyses confirmed that UV ns-laser processing of PDMS polymer in water causes chemical transformations and increases its chemical activation and hydrophilic properties.

\subsection{Electroless Metallization with Pt}

Thus, the chemically activated surface with increased hydrophilicity and homogeneous microstructure in the ablated zone and the absence of debris near ensure a very efficient process of deposition of Pt only within the laser ablated area by electroless metallization. SEM examinations show that platinum completely covers only the laser-treated areas (Figure 10). Circular grains are observed, which gather in adjacent wrists to form a cauliflower-like structure, which is typical for the electroless deposited coatings. Each grain resembles a flower with very fine spikes and petals with a size up to $100 \mathrm{~nm}$. Thus, platinum black coatings consisted of very small particles in size, which yields very high surface area. In addition, the optical microscope images reveal that the surface of the metal coatings appears as uniform black layers. This proves that the tracks are covered by platinum black films (their surface is rough and opaque and seems black relative to the transparent polymer) and do not have a silvery shiny look like a platinum film without having grain's structure. This is the most desired performance of platinum electrodes in MEAs development because of their effective conducting characteristics $[5,12,57]$. Platinum-black microelectrodes have been preferable used in producing implantable neural and neuroprosthetics interface devices performed like neural networks $[1,5,12,57]$. The sheet resistance of the Pt coatings deposited on our laser tracks is measured to be very low, varying between 1 and $8 \Omega$ /sq. These results are much promising and prove that the advanced approach for ns-laser ablation of PDMS in water activates the polymer surface most appropriately for successful further functionalization by electroless metallization.

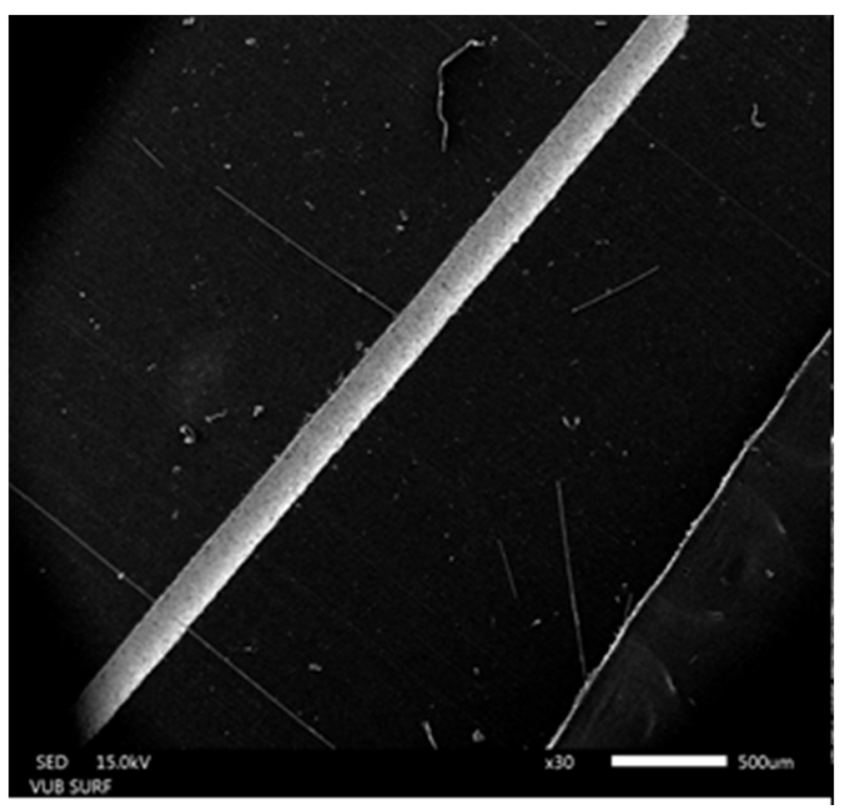

(a)

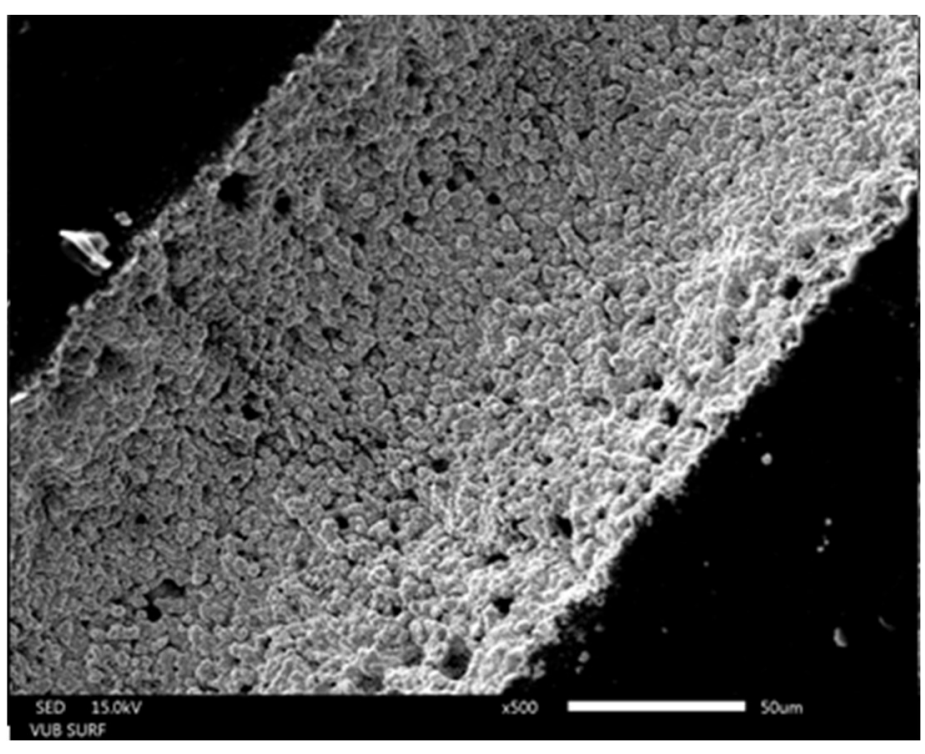

(b)

Figure 10. Cont. 


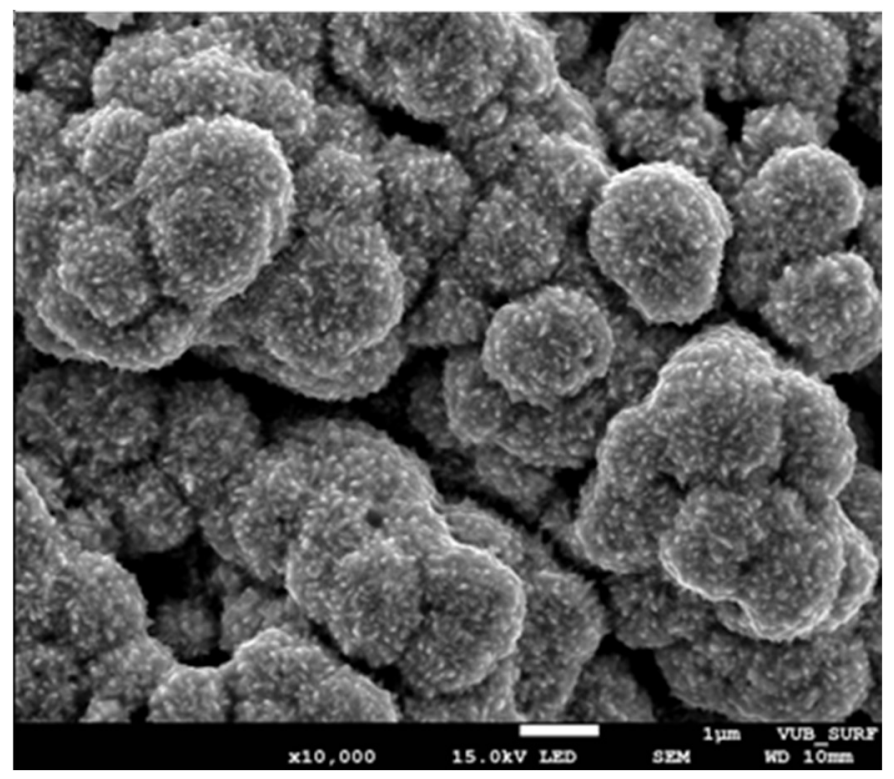

(c)

Figure 10. SEM images of electroless deposition of Pt layer on the track obtained by ns-laser ablation of PDMS (wavelength of $266 \mathrm{~nm}$, fluence $35.37 \mathrm{~J} \cdot \mathrm{cm}^{-2}$ ) in water. High-quality metal coating only on the laser-treated area is obtained. Different magnifications are applied to demonstrate $(\mathbf{a}, \mathbf{b})$ the absence of debris near beside the laser tracks, and (c) the cauliflower-like structure of the Pt layer, consisting fine nanograins.

In Figure 11 EDX analysis of the deposited Pt layer is presented. This determines the crystals formed during the electroless metallization are truly platinum.

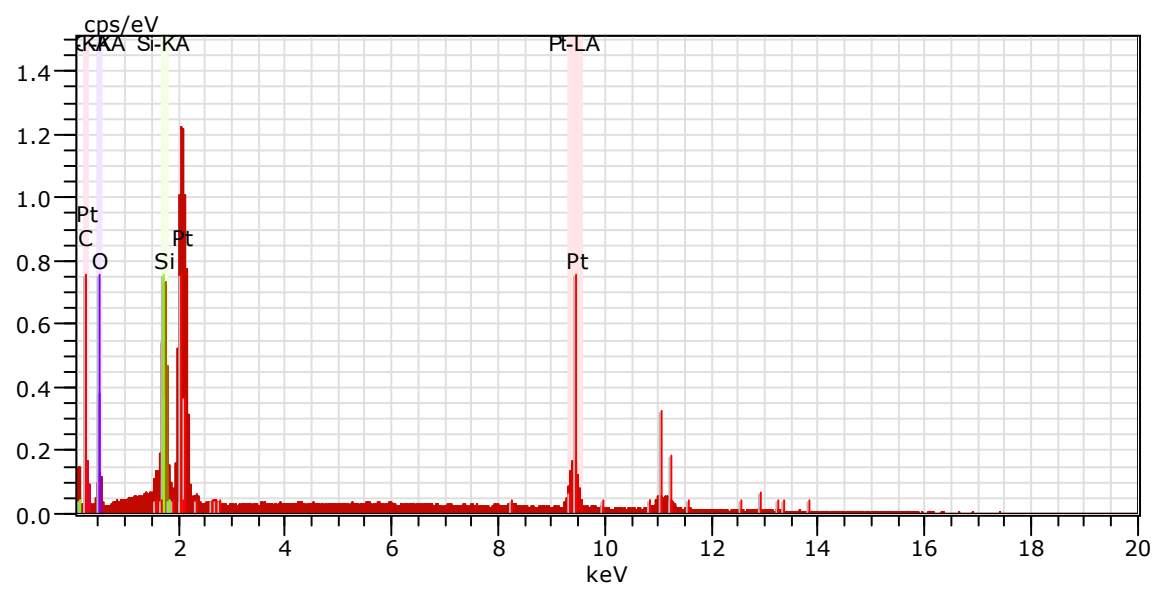

Figure 11. EDX image presented an elemental spectrum of electroless deposited Pt layer on the track obtained by ns-laser ablation of PDMS (wavelength of $266 \mathrm{~nm}$, fluence $35.37 \mathrm{~J} \cdot \mathrm{cm}^{-2}$ ) in water, confirming that the metal crystals are truly platinum.

The deposition of such a layer would significantly improve the electrical characteristics and the efficiency of the potential device because of its use as a neural implant. As a result of this treatment, we observed that the consumption of the deposited metal $(\mathrm{Pt})$ significantly decreases and, accordingly, no rapid depletion of metal in the autocatalytic bath happens.

Based on our preliminary and also on the current results, can be summarized that two main factors facilitated the electroless metal deposition and hence favorably influenced the formation of fine Pt grains: the first is the nanostructured morphology of the surface and the second is the hydrophilicity within the processed area both induced during ablation in water by UV ns-laser irradiation. 


\section{Conclusions}

To the best of our knowledge, we report on results related to a novel advanced method for micro/nanostructuring and chemical activating polymer surface, in the particular medical grade of PDMS elastomer, by single-scanned laser ablation in water by applying a certain number of overlapping nanosecond UV $(266 \mathrm{~nm}$ and $355 \mathrm{~nm})$ laser pulses on a unit area. Circulating water with a low rate and column height are fixed, while the laser fluence is the variable parameter. To highlight, the results obtained are: (1) free of debris laser tracks with (2) symmetric wide-open and U-shaped profiles with regular and smooth edges and (3) uniform nanostructured topography is produced; (4) no adjacent heataffected zones are observed; (5) hydrophilic properties of the laser-treated PDMS surface are induced by forming $\mathrm{Si}(-\mathrm{OH})$ functional group, which confer hydrophilic properties of the laser treated surface. The properties from (1) to (5) provide further (6) highly efficient functionalization of the laser-treated surface by autocatalytic (electroless) deposition of platinum $(\mathrm{Pt})$ excluding preliminary sensitization with $\mathrm{Sn}$ and chemical pre-activation with $\mathrm{Pd}$ (these two steps commonly precede the autocatalytic plating); (7) formation of platinum black layers with a cauliflower-like structure consisting fine nanograins with (8) low values of sheet resistance between 1 and $8 \Omega / \mathrm{sq}$; (9) the adjacent zones near the track contours are clear and not metalized.

The as-obtained metalized structures can meet the requirements in diverse application areas of stretchable MEAs interfacing technologies, but mainly in engineering solutions for the fabrication of high-definition flexible in-vitro and in-vivo neural networks. The proposed method could significantly contribute to: (1) miniaturization of the MEAs; (2) increasing the sensitivity and selectivity to the recorded and/or stimulated nerve pulses; (3) high mechanical matching between the device and the soft tissues; (4) low-cost and free of chemical contaminants process, since it is a no clean room-required method of fabrication.

\section{Patents}

The current results have been previously reported as a Patent application under number No 112728/03.05.2018 in the national patent office of Republic of Bulgaria. At present, this is a patent granted by the National Patent Office of the Republic of Bulgaria with registration number BG 67340/03.06.2021.

Author Contributions: Conceptualization, methodology, investigation, experiments on ns-laser ablation in water: N.S. and A.N.; E.I. and G.Y.: experiments on fs-laser ablation and analyses. K.K. and E.V.: electroless Pt metallization of the samples; E.V. and S.A.: XPS and SEM analyses and in-vestigations; D.K.: HRTEM and SAED analyses and investigation; N.F.: 3D laser microscope scanning and $\mu$-Raman analyses and investigation; N.N.; P.A.: investigation and formal analysis; D.T.: formal supporting analysis. All authors have read and agreed to the published version of the manuscript.

Funding: This research was funded by BNSF under the project KП-06-H38/5 2019.

Acknowledgments: The authors express their acknowledgments to the financial support of BNSF under the project No KП-06-H38/5 2019. The Bilateral joint research project "Laser-assisted processing of materials and characterization for top technology applications" between the Bulgarian Academy of Sciences (BAS) and the Romanian Academy of Sciences (RAS) 2020-2022 is also acknowledged. Research equipment of Distributed Research Infrastructure INFRAMAT, part of Bulgarian National Roadmap for Research Infrastructures, supported by Bulgarian Ministry of Education and Science is used in this investigation. The authors express their gratitude for the assistance in XPS analysis and part of the SEM investigations to Research Group SURF "Electrochemical and Surface Engineering" from Vrije Universiteit Brussels, Belgium. The authors would like to express their gratitude to Associate Professor Konstantin Kolev for his exceptional enthusiasm, which inspired our research team, and for his overall contribution to the launch and development of the research on this topic by our team-laser processing of medical grade PDMS elastomer and its functionalization by electroless $\mathrm{Pt}$ metallization, and especially for proposing and developing the method for electroless metallization with Pt without using sensitization by $\mathrm{Sn}$ and chemical activation of $\mathrm{Pd}$ on the treated surface, steps which usually preceding this process of metallization. 
Conflicts of Interest: The authors declare no conflict of interest.

\section{References}

1. Kim, R.; Joo, S.; Jung, H.; Hong, N.; Nam, Y. Recent Trends in Microelectrode Array Technology for In Vitro Neural Interface Platform. Biomed. Eng. Lett. 2014, 4, 129-141. [CrossRef]

2. Kim, J.; Im, C.; Lee, W.R. Plateau-Shaped Flexible Polymer Microelectrode Array for Neural Recording. Polymers 2017, 9, 690. [CrossRef] [PubMed]

3. Guo, L.; Guvanasen, G.S.; Liu, X.; Tuthill, C.; Nichols, T.R.; DeWeerth, S.P. A PDMS-Based Integrated Stretchable Microelectrode Array (isMEA) for Neural and Muscular Surface Interfacing. IEEE Trans. Biomed. Circuits Syst. 2013, 7, 1-10.

4. Thompson, C.H.; Zoratti, M.J.; Langhals, N.B.; Purcell, E.K. Regenerative Electrode Interfaces for Neural Prostheses. Tissue Eng. Part B Rev. 2016, 22, 125-135. [CrossRef] [PubMed]

5. Didier, C.M.; Kundu, A.; De Roo, D.; Rajaraman, S. Development of in vitro 2D and 3D microelectrode arrays and their role in advancing biomedical research. J. Micromech. Microeng. 2020, 30, 103001. [CrossRef]

6. Jin, H.; Jung, S.; Kim, J.; Heo, S.; Lim, J.; Park, W.; Chu, H.Y.; Bien, F.; Park, K. Stretchable Dual-Capacitor Multi-Sensor for Touch-Curvature-Pressure-Strain Sensing. Sci. Rep. 2017, 7, 10854. [CrossRef] [PubMed]

7. Makamba, H.; Kim, J.H.; Lim, K.; Park, N.; Hahn, J.H. Surface modification of poly(dimethylsiloxane) microchannels. Electrophoresis 2003, 24, 3607-3619. [CrossRef]

8. Liu, J.Q.; Tian, H.C.; Kang, X.Y.; Wang, M.H. Electrodes for Nerve Recording and Stimulation. In Micro Electro Mechanical Systems. Micro/Nano Technologies; Huang, Q.A., Ed.; Springer: Singapore, 2017; Volume 2. [CrossRef]

9. Cheung, K.C. Implantable microscale neural interfaces. Biomed. Microdevices 2007, 9, 923-938. [CrossRef]

10. Tsay, C.; Lacour, S.P.; Wagner, S.; Yu, Z.; Morrison, B. Stretchable Dielectric Material for Conformable Bioelectronic Devices. MRS Online Proc. Libr. 2006, 926, 202. [CrossRef]

11. Guo, L.; Kitashima, L.J.; Villari, C.R.; Klein, A.M.; DeWeerth, S.P. Muscle surface recording and stimulation using integrated PDMS-based microelectrode arrays: Recording-triggered stimulation for prosthetic purposes. In Proceedings of the 2009 IEEE Biomedical Circuits and Systems Conference, Beijing, China, 26-28 November 2009. [CrossRef]

12. Chuang, A.T.; Margo, C.E.; Greenberg, P.B. Retinal implants: A systematic review. Br. J. Ophthalmol. 2014, 98, 852-856. [CrossRef]

13. Hsieh, Y.; Chen, S.; Huang, W.; Hsu, K.; Gorday, K.A.V.; Wang, T.; Wang, J. Direct Micromachining of Microfluidic Channels on Biodegradable Materials Using Laser Ablation. Polymers 2017, 9, 242. [CrossRef]

14. Alrifaiy, A.; Lindahl, O.A.; Ramser, K. Polymer-Based Microfluidic Devices for Pharmacy, Biology and Tissue Engineering. Polymers 2012, 4, 1349-1398. [CrossRef]

15. Schuettler, M.; Stiess, S.; King, B.V.; Suaning, G.J. Fabrication of implantable microelectrode arrays by laser cutting of silicone rubber and platinum foil. J. Neural. Eng. 2005, 2, S121-S128. [CrossRef]

16. Lies, S.R.B.; Zhang, X.; Lyu, H.; Qin, H. Laser ablation of polymers: A review. Polym. Int. 2019, 68, 1391-1401. [CrossRef]

17. Suriano, R.; Kuznetsov, A.; Eaton, S.M.; Kiyan, R.; Cerullo, G.; Osellame, R.; Chichkov, B.N.; Levi, M.; Turri, S. Femtosecond laser ablation of polymeric substrates for the fabrication of microfluidic channels. Appl. Surf. Sci. 2011, 257, 6243-6250. [CrossRef]

18. Baset, F.; Villafranca, A.; Guay, J.; Bhardwaj, R. Femtosecond laser induced porosity in poly-methyl methacrylate. Appl. Surf. Sci. 2013, 282, 729-734. [CrossRef]

19. Surdo, S.; Piazza, S.; Ceseracciu, L.; Diaspro, A.; Duocastella, M. Towards nanopatterning by femtosecond laser ablation ofpre-stretched elastomers. Appl. Surf. Sci. 2016, 374, 151-156. [CrossRef]

20. Van Pelt, S.; Frijns, A.; Mandamparambil, R.; Den Toonder, J. Local wettability tuning with laser ablation redeposits on PDMS. Appl. Surf. Sci. 2014, 303, 456-464. [CrossRef]

21. Sola, D.; Milles, S.; Lasagni, A.F. Direct Laser Interference Patterning of Diffraction Gratings in Safrofilcon-A Hydrogel: Fabrication and Hydration Assessment. Polymers 2021, 13, 679. [CrossRef]

22. Sola, D.; Aldana, J.R.; Artal, P. The Role of Thermal Accumulation on the Fabrication of Diffraction Gratings in Ophthalmic PHEMA by Ultrashort Laser Direct Writing. Polymers 2020, 12, 2965. [CrossRef]

23. Hautefeuille, M.; Cabriales, L.; Pimentel-Domínguez, R.; Velázquez, V.; Hernández-Cordero, J.; Oropeza-Ramos, L.; Rivera, M.; Carreón-Castro, M.P.; Grether, M.; López-Moreno, E. New perspectives for direct PDMS microfabrication using a CD-DVD laser. Lab Chip 2013, 13, 4848-4854. [CrossRef] [PubMed]

24. Rytlewski, P.; Zenkiewicz, M. Application of lasers in metallization of thermoplastic and thermosetting polymers. J. Achiev. Mater. Manuf. Eng. JAMME 2013, 57, 59-67.

25. Frerichs, H.; Stricker, J.; Wesner, D.A.; Kreutz, E.W. Laser-induced surface modification and metallization of polymers. Appl. Surf. Sci. 1995, 86, 405-410. [CrossRef]

26. Dupas-Bruzek, C.; Robbe, O.; Addad, A.; Derozier, D. Transformation of medical grade silicone rubber under Nd:YAG and excimer laser irradiation: First step towards a new miniaturized nerve electrode fabrication process. Appl. Surf. Sci. 2009, 255, 8715-8721. [CrossRef]

27. Stankova, N.E.; Atanasov, P.A.; Nedyalkov, N.N.; Stoyanchov, T.R.; Kolev, K.N.; Valova, E.I.; Georgieva, J.S.; Armyanov, S.A.; Amoruso, S.; Wang, X.; et al. Fs- and ns-laser processing of polydimethylsiloxane (PDMS) elastomer: Comparative study. Appl. Surf. Sci. 2015, 336, 321-328. [CrossRef] 
28. Atanasov, P.A.; Stankova, N.E.; Nedyalkov, N.N.; Fukata, N.; Hirsch, D.; Rauschenbach, B.; Amoruso, S.; Wang, X.; Kolev, K.N.; Valova, E.I.; et al. Fs-laser processing of medical grade polydimethylsiloxane (PDMS). Appl. Surf. Sci. 2016, 374, $229-234$. [CrossRef]

29. Stankova, N.E.; Atanasov, P.A.; Nikov, R.G.; Nikov, R.G.; Nedyalkov, N.N.; Stoyanchov, T.R.; Fukata, N.; Kolev, K.N.; Valova, E.I.; Georgieva, J.S.; et al. Optical properties of polydimethylsiloxane (PDMS) during nanosecond laser processing. Appl. Surf. Sci. 2016, 374, 96-103. [CrossRef]

30. Armyanov, S.; Stankova, N.E.; Atanasov, P.A.; Valova, E.; Kolev, K.; Georgieva, J.; Steenhaut, O.; Baert, K.; Hubin, A. XPS and

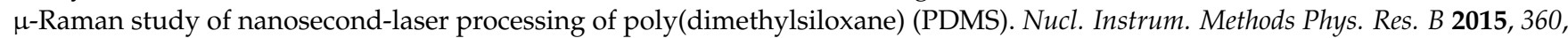
30-35. [CrossRef]

31. Armyanov, S.; Valova, E.; Kolev, K.; Tatchev, D.; Atanasov, P.; Stankova, N. Electroless deposition of nickel on biocompatible poly(dimethylsiloxane) after a laser processing as a pretreatment. Adv. Mater. Lett. 2018, 9, 101-106. [CrossRef]

32. Stankova, N.E.; Atanasov, P.A.; Nedyalkov, N.N.; Tatchev, D.; Kolev, K.N.; Valova, E.I.; Armyanov, S.A.; Grochowska, K.; Śliwiński, G.; Fukata, N.; et al. Laser-induced surface modification of biopolymers-Micro/nanostructuring and functionalization. J. Phys. Conf. Ser. 2018, 992, 012051. [CrossRef]

33. Laude, L.D. Process for the Metallization of Plastic Materials and Products Thereto Obtained. U.S. Patent 1997/5599592 A, 4 February 1997.

34. Dupas-Bruzek, C.; Drean, P.; Derozier, D. Pt metallization of laser transformedmedical grade silicone rubber: Last step toward a miniaturized nerve electrode fabrication process. J. Appl. Phys. 2009, 106, 074913. [CrossRef]

35. Sola, D.; Lavieja, C.; Orera, A.; Clemente, M.J. Direct laser interference patterning of ophthalmic polydimethylsiloxane (PDMS) polymers. Opt. Lasers Eng. 2018, 106, 139-146. [CrossRef]

36. Tham, N.C.Y.; Sahoo, P.K.; Kim, Y.-J.; Murukeshan, V.M. Ultrafast volume holography for stretchable photonic structures. Opt. Express. 2019, 27, 12196-12212. [CrossRef]

37. Farshchian, B.; Gatabi, J.R.; Bernick, S.M.; Park, S.; Lee, G.H.; Droopad, R.; Kim, N. Laser-induced superhydrophobic grid patterns on PDMS for droplet arrays formation. Appl. Surf. Sci. 2017, 396, 359-365. [CrossRef]

38. De Marco, C.; Eaton, S.M.; Suriano, R.; Turri, S.; Levi, M.; Ramponi, R.; Cerullo, G.; Osellame, R. Surface Properties of Femtosecond Laser Ablated PMMA. ACS Appl. Mater. Interfaces 2010, 2, 2377-2384. [CrossRef]

39. Laude, L.D.; Cochrane, C.; Dicara, C.; Dupas-Bruzek, C.; Kolev, K. Excimer laser decomposition of silicone. Nucl. Instrum. Methods Phys. Res. Sect. B 2003, 208, 314-319. [CrossRef]

40. Graubner, V.; Nuyken, O.; Wokaun, A.; Lazare, S.; Servant, L. Local chemical transformations in poly(dimethylsiloxane) by irradiation with 248 and $266 \mathrm{~nm}$. Appl. Surf. Sci. 2006, 252, 4781-4785. [CrossRef]

41. Stankova, N.; Nikolov, A.; Nedyalkov, N.; Atanasov, P. Method and System of Structuring and Activating Polymers with Laser Pulses. Patent Number BG 67340/03.06.2021, 3 June 2021.

42. Stankova, N.E.; Atanasov, P.A.; Nedyalkov, N.N.; Kolev, K.; Valova, E.; Armyanov, S. Laser processing of biopolymers for development of medical and high-tech devices. In Materials for Biomedical Engineering: Hydrogels and Polymer-Based Scaffolds, 1st ed.; Alina-Maria, H., Alexandru, M.G., Eds.; Elsevier: Amsterdam, The Netherlands, 2019; Chapter 15; pp. 487-526. ISBN 978-0-12-816901-8. [CrossRef]

43. Elaboudi, I.; Lazare, S.; Belin, C.; Talaga, D.; Labrugère, C. Underwater excimer laser ablation of polymers. Appl. Phys. A 2008, 92, 743-748. [CrossRef]

44. Chang, T.C.; Molian, P.A. Excimer pulsed laser ablation of polymers in air and liquids for micromachining applications. J. Manuf. Syst. 1999, 1, 1-17. [CrossRef]

45. Siegel, J.; Šuláková, P.; Kaimlová, M.; Švor`cík, V.; Hubá`cek, T. Underwater Laser Treatment of PET: Effect of Processing Parameters on Surface Morphology and Chemistry. Appl. Sci. 2018, 8, 2389. [CrossRef]

46. Waddell, E.A.; Locascio, L.E.; Kramer, G.W. UV Laser Micromachining of Polymers for Microfluidic Applications. JALA J. Assoc. Lab. Autom. 2002, 7, 78-82. [CrossRef]

47. Tangwarodomnukun, V.; Chen, H. Laser Ablation of PMMA in Air, Water and Ethanol Environments. Mater. Manuf. Process. 2015, 30, 685-691. [CrossRef]

48. Vardanyan, R.R.; Dallakyan, V.K.; Kerst, U.; Boit, C. Analysis of laser beam transmission inside media. Proc. NAS RA SEUA Tech. Sci. 2011, 64. Available online: https:/ /arar.sci.am/dlibra/publication/36492/edition/32776/content?ref=struct (accessed on 1 July 2021).

49. Takata, T.; Enoki, M.; Chivavibul, P.; Matsui, A.; Kobayashi, Y. Effect of Confinement Layer on Laser Ablation and Cavitation Bubble during Laser Shock Peening. Mater. Trans. 2016, 57, 1776-1783. [CrossRef]

50. Pozar, T.; Agrez, V.; Petkovsek, R. Laser-induced cavitation bubbles and shock waves in water near a concave surface. Ultrason. Sonochem. 2021, 73, 105456. [CrossRef]

51. Long, J.; Eliceiri, M.H.; Wang, L.; Vangelatos, Z.; Ouyang, Y.; Xie, X.; Zhang, Y.; Grigoropoulos, C.P. Capturing the final stage of the collapse of cavitation bubbles generated during nanosecond laser ablation of submerged targets. Opt. Laser Technol. 2021, 134, 106647. [CrossRef]

52. Jiang, M.Q.; Wu, X.Q.; Wei, Y.P.; Wilde, G.; Dai, L.H. Cavitation bubble dynamics during pulsed laser ablation of a metallic glass in water. Extreme Mech. Lett. 2017, 11, 24-29. [CrossRef] 
53. Charee, W.; Tangwarodomnukun, V.; Dumkum, C. Laser ablation of silicon in water under different flow rates. Int. J. Adv. Manuf. Technol. 2015, 78, 19-29. [CrossRef]

54. Dell'Aglio, M.; De Giacomo, A.; Kohsakowski, S.; Barcikowski, S.; Wagener, P.; Santagata, A. Pulsed laser ablation of wire-shaped target in a thin water jet: Effects of plasma features and bubble dynamics on the PLAL process. J. Phys. D Appl. Phys. 2017, 50, 185204. [CrossRef]

55. Nath, A.K. 9.06-Laser Drilling of Metallic and Nonmetallic Substrates. Compr. Mater. Process. 2014, 9, 115-175. [CrossRef]

56. Buenker, R.J.; Muiño, P.L. Quantum mechanical relations for the energy, momentum and velocity of single photons in dispersive media. Khimicheskaya Fyz. 2004, 23, 110-115. Available online: https://arxiv.org/ftp/physics/papers/0607/0607094.pdf (accessed on 11 July 2006).

57. Stanca, S.E.; Hänschke, F.; Ihring, A.; Zieger, G.; Dellith, J.; Kessler, E.; Meyer, H.-G. Chemical and Electrochemical Synthesis of Platinum Black. Sci. Rep. 2017, 7, 1074. [CrossRef] [PubMed] 